\title{
Impact of Phosphoproteomics in the Era of Precision Medicine for Prostate Cancer
}

\author{
Johnny R. Ramroop', Mark N. Stein ${ }^{2,3}$ and Justin M. Drake ${ }^{1,3,4 *}$ \\ ${ }^{1}$ Cancer Metabolism and Growth Program, Rutgers Cancer Institute of New Jersey, New Brunswick, NJ, United States, \\ ${ }^{2}$ Developmental Therapeutics/Phase I Program, Rutgers Cancer Institute of New Jersey, New Brunswick, NJ, United States, \\ ${ }^{3}$ Department of Medicine, Division of Medical Oncology and Rutgers Robert Wood Johnson Medical School, \\ New Brunswick, NJ, United States, ${ }^{4}$ Department of Pharmacology, Rutgers Robert Wood Johnson Medical School, \\ New Brunswick, NJ, United States
}

\section{OPEN ACCESS}

Edited by:

Stéphane Terry,

Institut Gustave Roussy, France

Reviewed by:

Andrew Burgess,

Anzac Research Institute, Australia Katarina Davalieva,

Macedonian Academy of Sciences and Arts, Macedonia

*Correspondence: Justin M. Drake justin.drake@cinj.rutgers.edu

Specialty section: This article was submitted to Genitourinary Oncology, a section of the journal Frontiers in Oncology

Received: 08 December 2017 Accepted: 29 January 2018 Published: 16 February 2018

Citation:

Ramroop JR, Stein MN and Drake JM (2018) Impact of Phosphoproteomics in the Era of Precision Medicine for Prostate Cancer. Front. Oncol. 8:28. doi: 10.3389/fonc.2018.00028
Prostate cancer is the most common malignancy in men in the United States. While androgen deprivation therapy results in tumor responses initially, there is relapse and progression to metastatic castration-resistant prostate cancer. Currently, all prostate cancer patients receive essentially the same treatment, and there is a need for clinically applicable technologies to provide predictive biomarkers toward personalized therapies. Genomic analyses of tumors are used for clinical applications, but with a paucity of obvious driver mutations in metastatic castration-resistant prostate cancer, other applications, such as phosphoproteomics, may complement this approach. Immunohistochemistry and reverse phase protein arrays are limited by the availability of reliable antibodies and evaluates a preselected number of targets. Mass spectrometry-based phosphoproteomics has been used to profile tumors consisting of thousands of phosphopeptides from individual patients after surgical resection or at autopsy. However, this approach is time consuming, and while a large number of candidate phosphopeptides are obtained for evaluation, limitations are reduced reproducibility, sensitivity, and precision. Targeted mass spectrometry can help eliminate these limitations and is more cost effective and less time consuming making it a practical platform for future clinical testing. In this review, we discuss the use of phosphoproteomics in prostate cancer and other clinical cancer tissues for target identification, hypothesis testing, and possible patient stratification. We highlight the majority of studies that have used phosphoproteomics in prostate cancer tissues and cell lines and propose ways forward to apply this approach in basic and clinical research. Overall, the implementation of phosphoproteomics via targeted mass spectrometry has tremendous potential to aid in the development of more rational, personalized therapies that will result in increased survival and quality of life enhancement in patients suffering from metastatic castration-resistant prostate cancer.

Keywords: clinical trials, kinases, kinase inhibitors, signaling pathways, phosphoproteomics, prostate cancer, mass spectrometry, targeted mass spectrometry

\section{CURRENT TREATMENT LANDSCAPE OF PROSTATE CANCER (PrCa)}

The male prostate, as well as early stage $\mathrm{PrCa}$, is dependent on androgens activating the androgen receptor (AR) for survival, growth, and proliferation (1). Prostate-specific antigen (PSA) is a serine protease that is secreted from the prostate and is transcriptionally regulated by AR. Thus, along with digital rectal exams, PSA-based screening is routinely used for early detection of $\mathrm{PrCa}$ (Figure 1) 


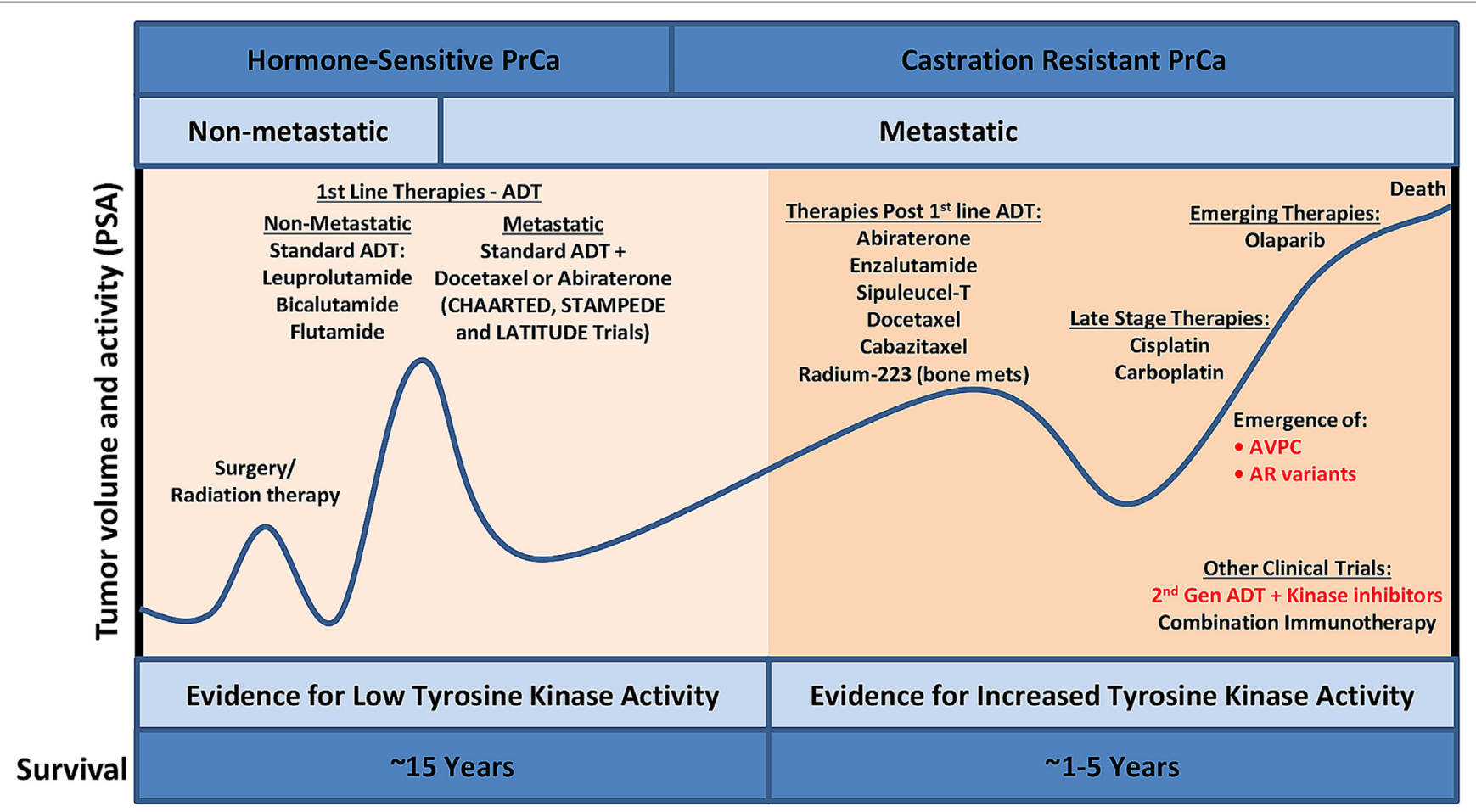

FIGURE 1 | PrCa progression and the current treatment landscape. Despite the availability of effective treatment for PrCa in its early stages, there are constant cycles of regression and recurrence due to therapeutic resistance via bypass mechanisms. Utilizing phosphoproteomics approaches to identify activated kinases in late-stage aggressive disease and precisely targeting these kinases with FDA-approved kinase inhibitors, in combination with other standard of care treatment, will lead to increased overall survival. ADT, androgen deprivation therapy; AVPC, aggressive variant prostate cancer; FDA, Food and Drug Administration; PrCa, prostate cancer; PSA, prostate-specific antigen.

although the magnitude of benefit from PSA screening continues to be debated (2). Biopsies are typically done to confirm PrCa, and if diagnosed with clinically significant disease (3), a patient most commonly has external beam radiation therapy or radical prostatectomy. Adjuvant androgen deprivation with radiation or adjuvant radiation after surgery may be administered in the setting of tumors with high risk of recurrence. Androgen deprivation therapy (ADT) that suppresses testicular function is typically first-line therapy for androgen-sensitive PrCa. A small additional survival benefit may be seen when first-generation oral AR inhibitors such as bicalutamide and flutamide are combined with ADT. Initial positive response to ADT is common by evidence of decline PSA levels in $90 \%$ of patients (4) and duration of response to therapy varies, with $5-10 \%$ of patients surviving 10 years after initiating ADT (5). In two recent phase III clinical trials (STAMPEDE and LATITUDE), hormone naive patients with locally advanced or oligometastatic disease starting first-line long-term ADT treatment were also given abiraterone acetate and prednisone $(6,7)$. Abiraterone acetate is a potent, second-generation inhibitor that blocks androgen synthesis, significantly decreasing circulating androgen below levels achieved with testicular suppression alone (8). In the STAMPEDE trial, inclusion of abiraterone acetate early in the treatment protocol resulted in a lower risk of death by $37 \%$. The 3 -year survival rate was $76 \%$ with standard ADT treatment alone and $83 \%$ with the standard care in combination with abiraterone acetate as well as a 14-month failure-free survival advantage (7). The results were also verified in a separate LATITUDE trial (6). In another phase III clinical trial (CHAARTED), patients with hormone-sensitive metastatic PrCa were given docetaxel in combination with firstline ADT treatment. The median overall survival with combination treatment was 13.6 months longer than with ADT alone (57.6 vs 44 months), nearly identical to the STAMPEDE and LATITUDE trials. A decrease in PSA to $<0.2 \mathrm{ng} / \mathrm{ml}$ at 12 months was $27.7 \%$ for the combination group compared to $16.8 \%$ for the ADT only group, and the median time for development of CRPC was increased (20.2 vs 11.7 months) (9). The results of these exciting clinical trials have prompted earlier use of docetaxel or abiraterone acetate plus standard ADT to delay time of metastatic castration-resistant PrCa (mCRPC) and ultimately death.

Metastatic castration-resistant PrCa is associated with poor prognosis with a mean survival time of 16-18 months (10). The US Food and Drug Administration (FDA)-approved therapies for mCRPC include chemotherapy agents (docetaxel and cabazitaxel), second-generation hormonal therapies (abiraterone acetate and enzalutamide), immunotherapy (sipuleucel-T), and radium-223. AR point mutations and amplifications have led to resistance to first-line ADT treatments, and since AR remains active in $\mathrm{MCRPC}$, these patients respond to abiraterone acetate and enzalutamide, but with a modest increase in overall survival 
of 3-4 months (11). A major resistance mechanism to abiraterone acetate and enzalutamide involve the presence of AR splice variants, such as ARv7 (12), possibly explaining the modest overall survival benefit of these agents in an unselected population. AR splice variants are truncated forms of wild-type AR where the ligand-binding domain is lost, activation is ligand independent, and these variants are constitutively active (13). It was recently shown that ARv7 mRNA detection in circulating tumor cells (CTCs) correlated with poor outcomes in patients with mCRPC who were treated with abiraterone acetate and enzalutamide (14). It is still unclear if AR splice variants are functionally contributing to treatment resistance, but ARv7 has developed into an important predictive biomarker for mCRPC patients taking either abiraterone acetate or enzalutamide. Another result of resistance to prolonged administration of abiraterone acetate and enzalutamide is the development of a lethal variant of mCRPC termed aggressive variant prostate cancer (AVPC; Figure 1). Indeed, AVPC was classified in 15\% of mCRPCs prior to the approval of abiraterone acetate and enzalutamide; however, this population shifted to $31 \%$ AVPC post-abiraterone acetate and enzalutamide (15). Several great reviews have been written on this disease variant (16-18), and recent work has classified AVPC into two distinct subtypes: AR-null expressing neuroendocrine (NE) differentiation markers and AR-null lacking markers of NE differentiation (double negative) (15). AVPC is characterized by several clinical and genetic features to include low PSA and AR protein expression, loss of retinoblastoma, TP53 mutations, overexpression of Aurora kinase A (AURKA), and amplification of N-Myc $(M Y C N)(19-21)$. Survival is typically less than a year with limited treatment options to include platinum-based chemotherapy. Based on the recent literature, it is becoming apparent that AR-independent pathways such as activated MAPK and FGFR kinase pathways are responsible for AVPC development and progression. Indeed, several clinical trials investigating AR-independent pathways are underway in $\mathrm{PrCa}$ including agents that target MEK and/or SRC (NCT01990196), AURKA (NCT01799278), PI3K/mammalian target of rapamycin (mTOR) (NCT02407054), and DNAPK (NCT01353625), although not all of these trials focus on AVPC.

\section{PERSONALIZED THERAPIES IN PrCa- CLINICAL EVIDENCE}

The treatment landscape of mCRPC and AVPC involve several "one-size-fits-all" approaches with no real stratification of patients or novel targeted therapies, with a few emerging exceptions. The observation that $\mathrm{AR}$ amplification and missense mutations are observed in nearly $70 \%$ of mCRPC cases (22) has led to the clinical paradigm where all patients are essentially treated with some form of androgen synthesis or AR function inhibitors. Other genetic alterations have been observed at high frequency (ETS gene rearrangements, TP53 mutations, and PTEN deletions) in mCRPC patients but are not yet predictive for any particular targeted therapy. Recent whole-genome and transcriptome sequencing efforts have identified several genetic aberrations in $\mathrm{MCRPC}$ patients at lower frequency to include TP53, RB1, PIK3CA/B,
$B R A F / R A F 1, B R C A 2, B R C A 1$, and $\operatorname{ATM}(22,23)$. In another study by Barbieri et al., the exomes of over 100 primary prostate adenocarcinomas and normal tissue pairs were sequenced and led to the identification of new recurrent mutations including $M E D 12, F O X A 1$, and $\operatorname{SPOP}(24)$. It was later shown that recurrent point mutations in SPOP in PrCa activates the PI3K/AKT/mTOR and AR signaling pathways providing functional evidence that this mutation may serve as a predictive biomarker to PI3K or AKT inhibitors in combination with antiandrogens $(25,26)$.

Mutations in DNA repair genes (e.g., BRCA2) are observed in approximately $10-15 \%$ of mCRPC cases (27). In ovarian cancer, FDA-approved poly ADP-ribose polymerase inhibitors, olaparib and rucaparib, have been used for the treatment of ovarian cancer in patients harboring the BRCA1, BRCA2, and other DNA repair gene mutations (28) and were sensitive to platinum-based chemotherapies (29). Indeed, recent clinical trials suggest that targeting these DNA repair mutations with PARP inhibitors may also be beneficial in men with mCRPC. In a phase II TOPARP-A trial, treatment with olaparib in patients who stopped responding to standard ADT treatment and who had aberrations in DNA repair genes (notably BRCA2 and ATM) led to a favorable response rate in $88 \%$ of patients (30). Response included $\geq 50 \%$ reduction in PSA and reduction in CTCs to $<5$ per $7.5 \mathrm{ml}$ of blood. Radiographic progression-free survival was longer in biomarker positive patients (median, 9.8 months) compared to biomarker negative (median, 2.7 months). Overall survival was also extended when compared between these two groups (median, 13.8 vs 7.5 months). Based on the data from this phase II TOPARP-A trial, olaparib received FDA breakthrough therapy designation in January 2016 to treat mCRPC patients with $B R C A 1 / 2$ or $A T M$ mutations who have received prior abiraterone acetate or enzalutamide therapy. Another phase II study is currently underway evaluating the efficacy of rucaparib in patients with $\mathrm{mCRPC}$ that harbor mutations in DNA repair genes (NCT02952534). In addition, in PTEN-deficient and TMPRESS2-ERG expressing PrCa tumor cells, rucaparib addition was synergistic when combined with radiation and suggested the use of rucaparib to radiosensitize PrCa cells as a useful strategy clinically (31). Similarly, other mutations and bypass mechanisms may be targeted to re-sensitize resistant cells or make them radiosensitive. For example, expression of the transcription factor antiprogrammed death ligand 1 (AP-1) is associated with $\mathrm{mCRPC}$ and constitutively active AP- 1 is dependent on EGFR and PI3K. Interestingly, inhibition of PI3K pathway suppresses AP-1 expression, sensitizing PrCa cells to gamma radiation, suggesting a combination of AKT inhibitors with radiation therapy as a novel strategy for treatment (32). Importantly, not all mCRPC patients with mutations in DNA repair genes will respond to olaparib due to secondary mutations that restore wild-type function or other activated cell survival pathways (33). Whole exome sequencing of circulating cell-free DNA (collected during the TOPARP-A trial) suggested that germline and somatic DNA repair mutations (BRCA2 and PALB2) reverted back in frame as the mechanism behind resistance to olaparib providing a novel platform for assessing predictive biomarkers in this patient cohort (28).

Currently, about $20-30 \%$ of mCRPC patients resistant to abiraterone acetate or enzalutamide may benefit from stratification 
and targeted therapy trials as described above. However, the remaining $70-80 \%$ of $\mathrm{mCRPC}$ patients are devoid of activating mutations in genes that lead to the "smoking gun" hypothesis identifying obvious targeted therapy applications based on the genomic data alone. As we get better at targeting AR for mCRPC, it is becoming clearer that bypass kinase pathways are important mediators of treatment resistance in MCRPC and AVPC and the development of new tools or utilization of existing ones to identify these pathways are becoming necessary. Indeed, future clinical therapies may rely on the precise targeting of these select kinases in this disease in combination with other agents to prolong survival.

\section{TOOLS TO ASSESS KINASE SIGNALING PATHWAYS IN CANCER}

\section{Reverse Phase Protein Arrays (RPPAs) and Immunohistochemistry (IHC)}

Antibody-based methodologies for the assessment of signaling networks in CRPC (and other cancers) include both IHC $(34,35)$ and RPPA $(36,37)$. These antibody approaches are amenable to use on clinical tissues such as biopsies and do not require specialized instruments. However, these assays can be time consuming with respect to optimizing staining protocols for each antibody (IHC), and only a select few phosphosite-specific antibodies are robust enough and are commercially available, limiting the analysis to a predefined set of targets. Also, neither approach is particularly high throughput as IHC staining typically analyzes one protein at a time and RPPA can measure up to a couple hundred from a given tissue section or biopsy. Overall, RPPAs and IHC-based approaches work very well for detecting known and predefined pathways for a given tumor type and to date are better with low sample amounts. However, they are not well suited for easy customization or discovery-based investigation of a large number of cell signaling pathways such as with mass spectrometry (MS)-based approaches.

\section{MS-Based Phosphoproteomics}

Mass spectrometry is an analytical technique that involves the ionization of a molecule and subsequent detection and identification of the fragmented ions based on its mass-to-charge $(\mathrm{m} / \mathrm{z})$ ratio. There are two main MS-based proteomics approaches, top-down and bottom-up. The top-down approach involves analyzing whole proteins, while the bottom-up method involves measuring the peptides from digested proteins. These two approaches can be used for either shotgun or targeted platforms. In both approaches, the sample analytes are injected and eluted from a reverse-phase column, ionized, and sorted based on the $\mathrm{m} / \mathrm{z}$ ratio within the mass spectrometer instrument. The fragment and parent masses are used to determine the identity of the analyte. While MS instruments are expensive, MS does provide the advantage of high data collection power and has the customizable capability of analyzing small, complex sample amounts with high sensitivity, repeatability, and resolution.

Phosphoproteomics is the identification and characterization of proteins with phosphorylation as a posttranslational modification (PTM). Phosphoproteomics provide insight into proteins that are important for regulating essential signaling pathways and cellular processes and may lead to new potential drug targets. In shotgun phosphoproteomics, protein samples are enzymatically digested into peptides and phosphopeptides (Figure 2A). Digestion is predominantly performed using trypsin because of its high specificity, availability, and ease of use. The limitation of the use of trypsin alone in bottom-up phosphoproteomics is that a comprehensive view of the full phosphoproteome may be compromised as a result of missing particular PTM sites, missed cleavages, or too small peptides. However, LysC can be used in conjunction with trypsin to reduce some missed cleavage events, increasing PTM site coverage. The use of alternative proteases such as chymotrypsin, LysN, AspN, GluC, and ArgC may also help with limitations of trypsin digestion, but these proteases must be used in separate experimental preparations to eliminate the generation of phosphopeptides that are too small for MS detection (38). It was initially believed that up to $30 \%$ of all human proteins may be modified by phosphorylation (39). More recent findings indicate that at least approximately $75 \%$ of the proteome can be phosphorylated (40). Phosphoserine and phosphothreonine modifications represent approximately $98 \%$ of the phosphoproteome ( $~ 86$ and $\sim 12 \%$, respectively), while tyrosine phosphorylation accounts for approximately $2 \%$ of protein phosphorylation in cells (41). Due to the low abundance of phosphopeptides in complex biological tissue, enrichment steps such as immobilized metal affinity chromatography, metal oxide surfaces using titanium oxide $\left(\mathrm{TiO}_{2}\right)$, antibody-based enrichment (e.g., 4G10, used for phosphotyrosine enrichment), or a combination of these approaches are necessary (Figures 2B,C) $(42,43)$. The digested and enriched phosphopeptides are then analyzed by the mass spectrometer (Figure 2D), and the identified phosphopeptides are collected for data analysis.

While very powerful, shotgun phosphoproteomics does have some limitations. In general, higher abundant phosphopeptides are sampled more frequently, while lower abundant phosphopeptides are sampled less frequently. In addition, high variability of sampling between MS runs can exist as lower abundant phosphopeptides may be sequenced in some samples, but not in others, creating a "missing data" problem that can complicate statistical analyses (44). While thousands of phosphopeptides are identified in complex biological specimens, tool to evaluate and comprehend the large amount of phosphopeptide information is another main challenge. This has led to the development of resources providing a platform for data processing ranging from annotation and pathway enrichment to generating pathway networks and protein-protein interactions such as MaxQuant (45), Skyline (46), and kinase-substrate enrichment analysis $(47,48)$. A couple excellent reviews describe these software programs in more detail $(49,50)$ and will not be discussed in this review.

\section{PHOSPHOPROTEOMICS IN PrCa}

Mass spectrometry-based proteomics and phosphoproteomics on cell lines, mouse xenografts, and clinical tissue samples have 


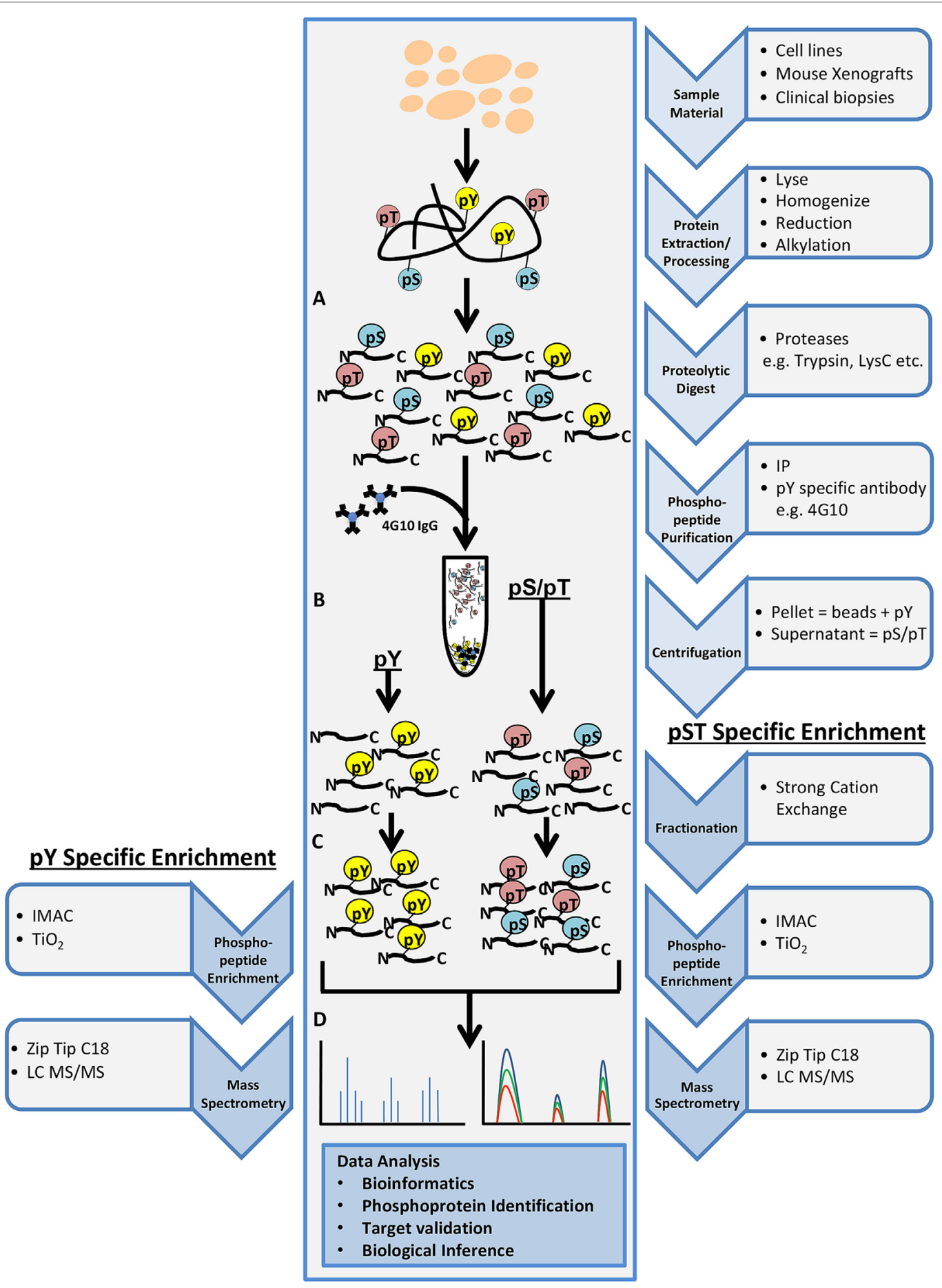

FIGURE 2 | General workflow for shotgun phosphoproteomics analysis. Tissue samples may include cultured cell lines, mouse xenografts, or clinical biopsy specimens. Tissue samples are lysed, homogenized, reduced, alkylated, and digested with the appropriate protease(s) (A). Phosphopeptide purification by immunoprecipitation (IP) and centrifugation will yield two fractions: pellet containing phosphotyrosine peptides (pY) and supernatant containing phosphoserine/ phosphothreonine (pS/pT) peptides (B). Strong cation exchange is performed for the pS/pT peptides fraction before phosphopeptide enrichment step for both fractions [immobilized metal affinity chromatography (IMAC) or Titanium oxide $\left(\mathrm{TiO}_{2}\right)$ ] (C) and analysis by LC-MS/MS (D).

been used to characterize a wide array of different cancer types as well as identify tumor associated signatures that are involved in cancer progression or resistance to standard therapies. Here, we discuss some of the insights gained from MS-based proteomics and phosphoproteomics in PrCa as well as other cancers such as ovarian, lung, breast, and colorectal. 
In a previous study by our group, nearly $50 \%$ of CRPC tissues showed increased levels of overall tyrosine phosphorylation compared to hormone naive $\mathrm{PrCa}$ (51), suggesting that CRPC tissues are prime candidates for investigating the role of activated kinases driving resistance to hormonal therapies. Since there are no clear common mutational drivers explaining this observed increase in tyrosine phosphorylation in CRPC, we discuss some landmark papers that utilized MS-based phosphoproteomics that identified activated kinase pathways, nominating new therapeutic targets in this disease.

Our group previously identified over 8,000 unique phosphopeptides in mCRPC patient tumors obtained at rapid autopsy using MS-based phosphoproteomics $(48,52)$. The phosphopeptide signatures differentiated treatment naive PrCa from mCRPC and suggested that metastatic sites within the same patient were highly similar in their signaling networks but differed across patients (52). Some of the activated kinases identified include SRC, EGFR, MEK1, JAK2, AKT, MAPK1/3, and PI3K. Further, we connected both SRC and MAPK1/3 activity to nearly $70 \%$ of the MCRPC patients who were evaluated in this study, suggesting that a combination of targeted agents to these two kinases may be beneficial clinically if administered to the correct patient population.

Our group also demonstrated that the integration of our phosphoproteomic datasets with genomic and transcriptomic data provided additional pathway information relevant to signaling networks in mCRPC. By using Tied Diffusion through Interacting Events (53) to integrate differentially expressed transcriptional regulators, genomic mutations, and activated kinases in mCRPC, a list of signaling networks with druggable kinase pathways were generated. From MSigDB gene sets, after incorporating phosphoproteomics data, six major signaling pathways were found to be upregulated in MCRPC tumors including the cell signaling pathway, DNA repair pathway, MAPK/AKT/mTOR, and nuclear receptor pathway (48). When the phosphoproteomics data were not included, these signaling pathways were not as highly enriched. Therefore, the integration of phosphoproteomic data enhanced and validated pathway networks determined by genomic and transcriptional analyses. In addition, we developed a patient-specific, rank order list of kinases predicted to drive the mCRPC tumors in each patient. Since we previously showed patterns of intrapatient similarity of kinase signaling, the collection of an easy accessible biopsy may be all that is needed to identify the activated pathways in each patient.

Our group also began to functionally assess these targets in preclinical models of metastatic development. Over 100 kinases were prioritized based on the phosphoproteomic, gene expression, or genomic information in mCRPC tissues and evaluated in a metastatic tail vein model via overexpression in non-metastatic mouse cell lines. We found that 20 kinases promoted metastases in an in vivo lung colonization screen. In a second metastatic screen, we overexpressed these 20 kinases in human RWPE- 1 cells and identified RAF family (ARAF, BRAF, and CRAF), MERTK, and NTRK2 tyrosine kinases to promote bone and visceral metastases (54). These data suggested the potential contribution of wild-type kinases in PrCa metastasis and identified some candidates for future preclinical and clinical targeting.
Since our initial publications assessing the phosphoproteome of both mouse and human tumors, other groups have begun using phosphoproteomics to address different aspects of PrCa biology. By using quantitative MS-based phosphoproteomics of $\mathrm{PrCa}$ cell lines DU145 and PC3, an increase in activated focal adhesion kinase (FAK) at residues Y397 and Y596 was observed in docetaxel resistant DU145 (FAK Y397) and PC3 (FAK Y596) cell lines (55). The $\mathrm{Y} 397$ phosphosite serves as a binding site for proteins such as SRC, SHC, and the regulatory subunit of PI3K, while the Y596 site falls within the central kinase domain. Treatment with the FAK inhibitor PF-00562271 reduced phosphorylation of FAK but not AKT and had no effect on cell viability. Docetaxel alone reduced phosphorylation of FAK and AKT, and when added in combination with PF-00562271, there was an additive effect and a rescue of chemoresistance. These data suggested that in $\mathrm{mCRPC}$ patients who became resistant to docetaxel treatment due to increased FAK activation, combination therapy with the FAK inhibitor PF-00562271 and docetaxel may be administered to overcome chemoresistance (55).

In another study, protein phosphorylation in LNCaP PrCa cell line xenografts grown in intact and castrated mice identified hyperphosphorylation of signaling proteins including MEK, LYN, PRAS40, YAP1, and PAK2 (56). Also, analysis of CRPC clinical samples showed increased PAK2 and YAP1 levels. In androgenindependent PC3 xenografts, the PAK2 inhibitor PF-3758309 and YAP1 inhibitor verteporfin inhibited tumor growth (56). These data suggested that PAK2 and YAP1 as possible key players during the transition from a hormone naive to a castration resistance state.

Another study of parental LNCaP cells and an androgenindependent version of LNCaP revealed over 60 phosphopeptides that are involved in androgen-independent PrCa cell growth, including thyroid hormone receptor-associated protein 3 (THRAP3) (57). THRAP3 is a transcription coactivator of AR, and hypophosphorylation of residues S248 and S253 were found in androgen-independent LNCaP cells. In addition, the interacting protein partners in both phosphorylated and unphosphorylated states of THRAP3 were different. By using non-phosphorylatable mutants (S248A/S253A) and phosphomimetic forms (S248D/ S253D) of THRAP3, the interacting partners were related to RNA splicing/processing, suggesting that phosphorylated THRAP3 at S248 and S253 regulates transcriptional programs leading to androgen-independent PrCa cell growth.

Other studies using the parental LNCaP PrCa cell line identified phosphopeptides corresponding to several actionable kinase targets. These included BRAF, PIK3C2G, STK39, CDK1, MAPK2, AKT1, PRKD1, casein kinase 1 and 2 (CK2A1, CK2A2), and glycogen synthase kinase 3 (GSK3B) (58-60).

The above are most of the examples of work that have demonstrated the value of utilizing phosphoproteomic profiling to reveal regulatory mechanisms and pathways crucial for drug resistance and recurrence in PrCa cell lines and tissues (Table 1). Interestingly, most of these kinases are not mutated at high frequencies at all in mCRPC (Figure 3). In addition to MS, antibody-based proteomic and phosphoproteomics analyses such as IHC (51, 56, 61-63) and RPPA (64-66) have also revealed activated kinases that are involved in disease progression and drug 
TABLE 1 | Summary of phosphoproteomic studies in prostate cancer.

\begin{tabular}{|c|c|c|c|}
\hline \multicolumn{4}{|c|}{ Kinases and regulatory proteins altered in prostate cancer tissues and cell lines } \\
\hline Regulatory protein/kinase & Kinase type/function & Source of material & Reference \\
\hline SRC & Tyrosine kinase & mCRPC patient tumors at rapid autopsy vs treatment naïve primary prostate tissue & Drake et al. (52) \\
\hline EGFR & Tyrosine kinase & Prostate cancer cell lines: 22Rv1, LNCaP, DU145 and C4-2 & Drake et al. (48) \\
\hline MEK1 & Serine/threonine kinase & Prostate cancer cell line derived xenografts: $22 \mathrm{R} v 1$ and LNCaP & \\
\hline JAK2 & Tyrosine kinase & & \\
\hline AKT1 & Serine/threonine kinase & & \\
\hline MAPK1 & Serine/threonine kinase & & \\
\hline MAPK3 & Serine/threonine kinase & & \\
\hline FAK & Tyrosine kinase & $\begin{array}{l}\text { Docetaxel resistant DU145 and PC3 prostate cell lines vs Parental DU145 and PC3 } \\
\text { prostate cancer cell lines }\end{array}$ & Lee et al. (55) \\
\hline MEK1 & Serine/threonine kinase & Parental LNCaP prostate cancer cell line & Jiang et al. (56) \\
\hline LYN & Tyrosine kinase & & \\
\hline YAP1 & Transcriptional coactivator & & \\
\hline PAK2 & Serine/threonine kinase & & \\
\hline THRAP3 & Transcription coactivator & Parental and androgen-independent LNCaP prostate cell lines & Ino et al. (57) \\
\hline AKT1 & Serine/threonine kinase & Parental LNCaP prostate cancer cell line & Giorgianni et al. (58) \\
\hline BRAF & Serine/threonine kinase & & \\
\hline CDK1 & Serine/threonine kinase & & \\
\hline STK39 & Serine/threonine kinase & & \\
\hline PIK3C2G & Serine/threonine kinase & & \\
\hline PRKD1 & Serine/threonine kinase & & \\
\hline CK1A & Serine/threonine kinase & Parental LNCaP prostate cancer cell line & Myung and Sadar (60) \\
\hline CK2A1 & Serine/threonine kinase & & \\
\hline GSK3B & Serine/threonine kinase & & \\
\hline AKT1 & Serine/threonine kinase & Parental LNCaP prostate cancer cell line & Chen et al. (59) \\
\hline MAPK1 & Serine/threonine kinase & & \\
\hline MAPK3 & Serine/threonine kinase & & \\
\hline
\end{tabular}

Some of the potentially key druggable targets identified via MS-based phosphoproteomics that were highlighted in this review for prostate cancer emphasizing the paucity of global phosphoproteomic studies in clinical specimens.

resistance. These identified regulatory proteins and pathways can also serve as potential therapeutic targets.

\section{CLINICAL TRIALS: KINASE INHIBITORS AND PrCa}

Kinase pathways validated from various studies mentioned above would strongly act as clinical biomarkers for the evaluation of patients' tumor kinase activation profiles. To date, biopsy-driven, therapeutic efforts aimed at targeting wild-type kinases that are activated in mCRPC are not performed. Mounting evidence that cancer is a disease of deregulated signaling pathways has led to the development of signaling-based targeted therapies for various human tumor types based on genomic mutations of these pathways. There are a number of FDA-approved kinase inhibitors for the treatment of cancer such as non-small-cell lung cancer, myeloma, head and neck cancer, and breast cancer, just to name a few (Table 2). These agents target kinases that have also been shown to be activated or upregulated in MCRPC making these inhibitors potentially beneficial to patients with $\mathrm{MCRPC}$ if used in the right context or combination. Currently, there are over 900 clinical trials in progress in PrCa in the United States with 85 studies in phase III. Of these, only 21 are investigating kinase inhibitors, alone or in combination, for PrCa. Below are some examples of previous clinical trials utilizing kinase inhibitors and the outcomes.
Bevacizumab, which blocks VEGF signaling, was assessed in a phase III trial comparing the treatment of docetaxel/prednisone alone or in combination with bevacizumab in patients with mCRPC. Combination treatment resulted in a 2.4-month improvement in progression-free survival, but no difference in median survival (73). Sorafenib was shown to prevent disease progression and cause regression of bone metastases in some patients but without decreasing PSA levels (74), and sunitinib also induced a partial radiographic response but had a minimal effect on PSA levels in both treatment naive and docetaxel-treated CRPC patients (75).

Mammalian target of rapamycin inhibitors as a single agent had minimal effect in mCRPC (76), but in combination with docetaxel, it was shown to reverse drug resistance in PrCa cell lines (77). In patients with PTEN and other genetic aberrations where the AKT pathway is activated, targeting the AKT pathway in combination with mTOR inhibitors was shown to induce apoptosis. The AKT inhibitor, perifosine, in a phase II trial in patients with recurrent, hormone-sensitive PrCa did not meet prespecified PSA criteria for response with only $20 \%$ of patients showing a reduction in PSA, but none had a decline greater than $50 \%$. As a single agent, there was only modest clinical activity with perifosine but other AKT inhibitors are in clinical trials in combination studies with docetaxel (NCT02121639), bicalutamide (NCT01251861), and abiraterone (NCT01485861). Everolimus, another mTOR inhibitor, was FDA approved in 2016 for the treatment of patients with NE tumors of pancreatic origin. In a phase I study, everolimus 


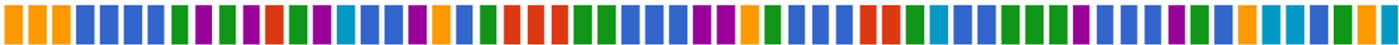

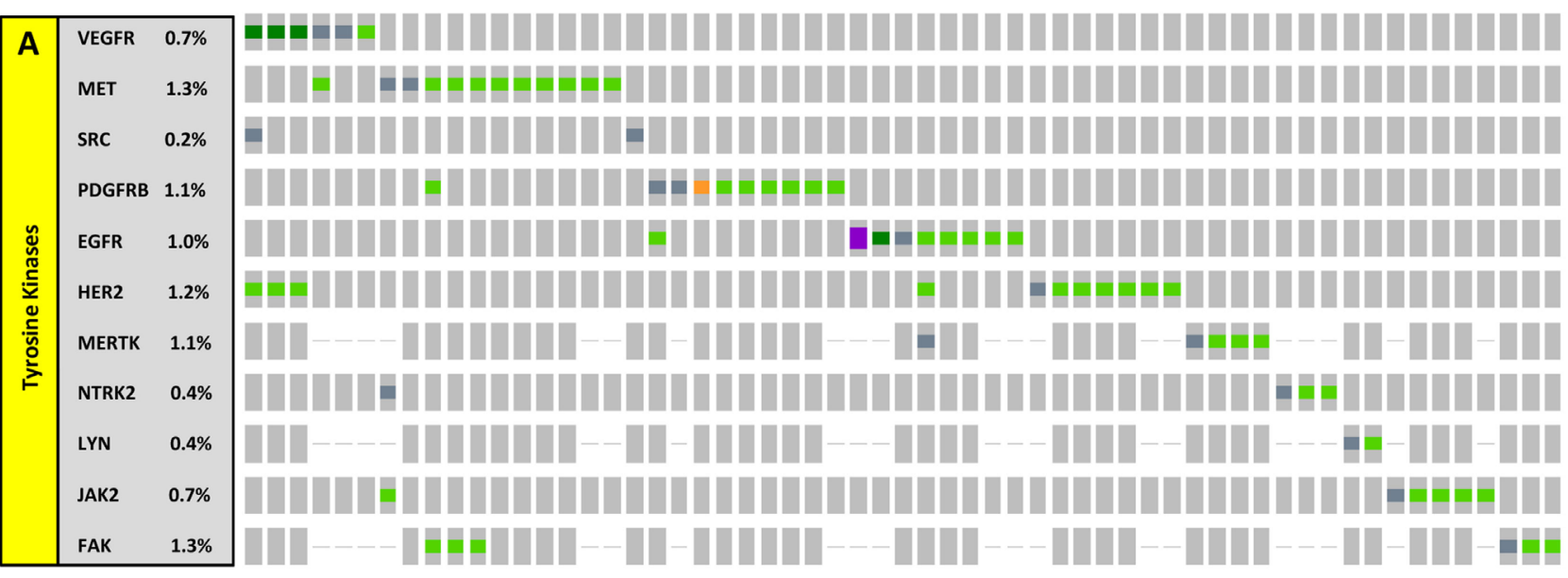

\section{.}
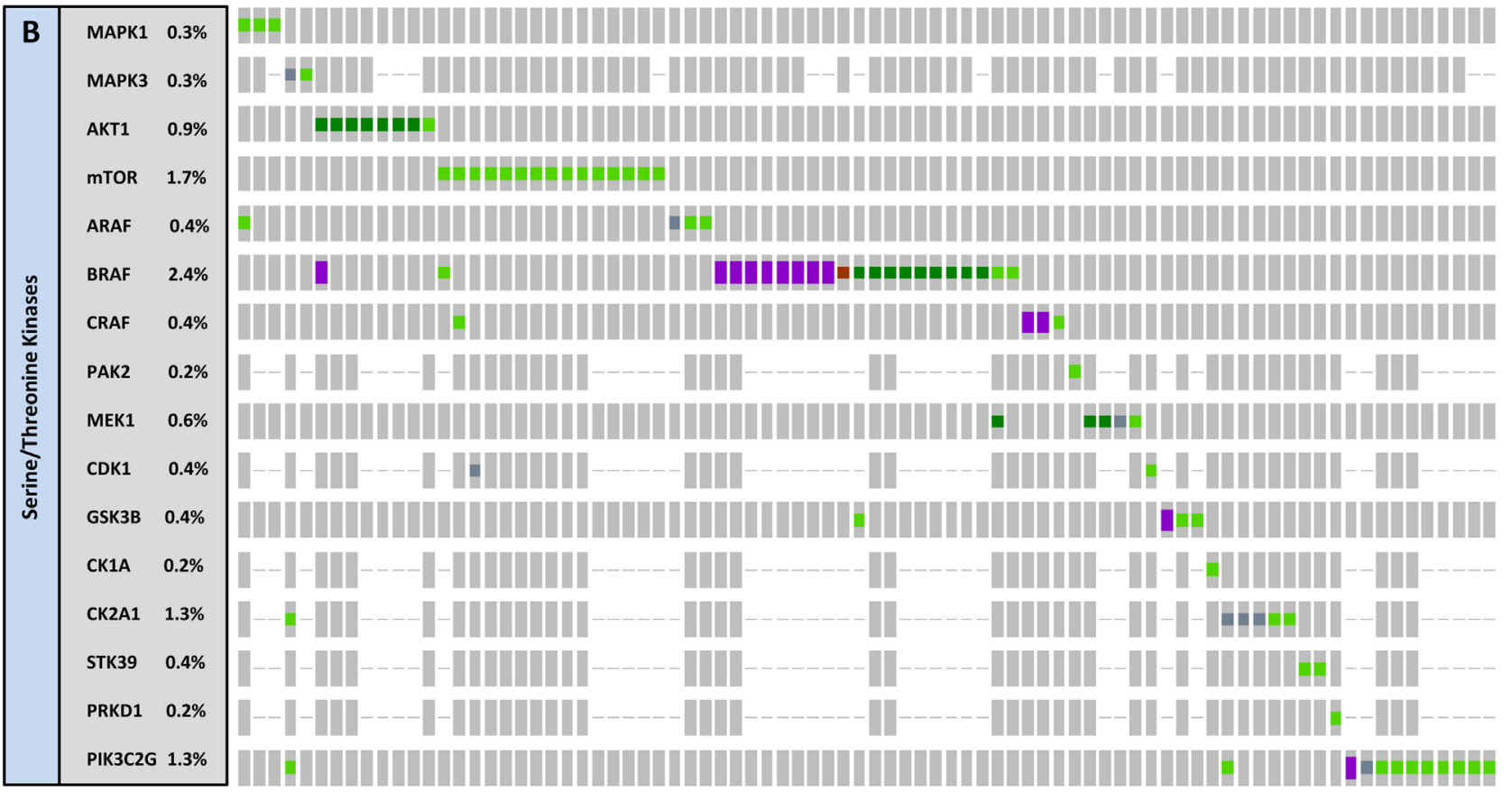

\section{Genetic Alteration}

No alterations $\quad$ Fusion Truncating Mutation (putative passenger) Inframe Mutation (putative passenger)

- Missense Mutation (putative driver) Missense Mutation (putative passenger) - Not sequenced

\section{Studies Included}

Neuroendocrine Prostate Cancer (Trento/Cornell/Broad 2016)

Prostate Adenocarcinoma (MSKCC, Cancer Cell 2010)

Metastatic Prostate Cancer, SU2C/PCF Dream Team (Robinson et al., Cell 2015)

Prostate Adenocarcinoma, Metastatic (Michigan, Nature 2012)

Prostate Adenocarcinoma (Fred Hutchinson CRC, Nat Med 2016)

MSK-IMPACT Clinical Sequencing Cohort in Prostate Cancer (MSK, JCO Precision Oncology 2017)

FIGURE 3 | Continued 
FIGURE 3 | Mutations in select kinases in metastatic castration-resistant prostate cancer (mCRPC). Columns represent individual patients, and rows represent genetic alterations detected in tyrosine (A) or serine/threonine (B) kinases. For the 6 studies mentioned (22, 23, 67-70), samples from a total of 900 patients were sequenced revealing mutations in 59 patients ( 7\%) for tyrosine kinases and in 82 patients ( 9\%) for serine/threonine kinases. Importantly, driver mutations were only observed in 4 patients ( 0.4\%) for tyrosine kinases and 19 patients ( 2\%) for serine/threonine kinases, suggesting that a very small fraction of the mCRPC population have genomic identifiers of kinase activity. The proportion of patients with alterations in each kinase is listed on the left. Only patients with alterations are represented. Data were extracted from cBioPortal $(71,72)$.

TABLE 2 | List of FDA-approved kinase inhibitors to date with the disease and kinase targets.

\begin{tabular}{|c|c|c|}
\hline Kinase inhibitor & Disease & Kinase target/s \\
\hline Acalabrutinib & Mantle cell lymphoma & BTK \\
\hline Afatinib & NSCLC, squamous NSCLC & EGFR, ERBB2, ERBB4 \\
\hline Alectinib & ALK-positive NSCLC & ALK, RET \\
\hline Axitinib & Renal cell carcinoma & VEGFR1, VEGFR2, VEGFR3, PDGFR $\beta$ \\
\hline Bosutinib & $\mathrm{CML}$ & BCR-ABL, SRC, LYN, HCK \\
\hline Brigatinib & ALK-positive NSCLC after crizotinib & ALK, ROS1, IGF-1R, FLT3, EGFR \\
\hline Cabozantinib & Metastatic medullary thryoid carcinoma, RCC & RET, MET, VEGFR1, VEGFR2, VEGFR3, KIT, NTRK2, FLT3, AXL, TEK \\
\hline Ceritinib & ALK-positive NSCLC after crizotinib & ALK, IGF-1R \\
\hline Cobimetinib & Melanoma with BRAF V600E/K mutation with vemurafenib & $\mathrm{MEK} 1 / 2$ \\
\hline Crizotinib & ALK-positive NSCLC, ROS1-positive NSCLS & ALK, MET, ROS1, MST1R \\
\hline Dabrafenib & Melanoma and NSCLC with BRAF V600E & BRAF \\
\hline Dasatinib & $\mathrm{CML}, \mathrm{ALL}$ & BCR-ABL, SRC, LCK, YES, FYN, KIT, EPHA2, PDGFRB \\
\hline Erlotinib & NSCLC, pancreatic cancer & EGFR \\
\hline Everolimus & ERBB2-negative breast cancer, PNET, RCC, RAML, SEGA & mTOR, FKBP12 \\
\hline Gefitinib & NSCLC & EGFR \\
\hline Ibrutinib & MCL, CLL & BTK \\
\hline Imatinib & $\mathrm{CML}$ & BCR-ABL, KIT, PDGFR \\
\hline Lapatinib & Metastatic breast cancer & EGFR, ERBB2 \\
\hline Lenvatinib & Differentiated thyroid cancer & VEGFRs, FGFRs, PDGFR, KIT, RET \\
\hline Midostaurin & AML with FLT3-positive mutation & FLT3 \\
\hline Neratinib & ERBB2-positive breast cancer & ERBB2 \\
\hline Nilotinib & $\mathrm{CML}$ & BCR-ABL, PDGFR, KIT, CSF1R, DDR1 \\
\hline Nintedanib & Idiopathic pulmonary fibrosis & FGFRs, PRGFR $\alpha / \beta$, VEGFRs, FLT3 \\
\hline Osimertinib & NSCLC & EGFR T970M \\
\hline Palbociclib & ER-positive/Her2-negative breast cancer & $\mathrm{CDK} 4 / 6$ \\
\hline Pazopanib & Renal cell carcinoma & VEGFRs, PDGFR $\alpha / \beta$, FGFR1/3, KIT, ITK, LCK, FMS \\
\hline Ponatinib & $\mathrm{CML}$ & BCR-ABL, VEGFR, PDGFR, FGFR, EPHR, SRC, KIT, RET, TEK, FLT3 \\
\hline Regorafenib & Colorectal cancer & VEGFRs, BCR-ABL, RET, KIT, FGFR1/2, PDGFR $\alpha / \beta$, EPHA2, BRAF \\
\hline Ribociclib & HR-positive/EGFR-negative breast cancer & $\mathrm{CDK} 4 / 6$ \\
\hline Ruxolitinib & Myelofibrosis, PV & JAK1, JAK2 \\
\hline Sirolimus & Renal transplant lymphangioleiomyomatosis & FKBP12, mTOR \\
\hline Sorafenib & Hepatocellular, renal, thyroid carcinoma & BRAF, CRAF, KIT, FLT3, RET, VEGFRs, PDGFR $\beta$ \\
\hline Sunitinib & GIST, renal cell carcinoma, PNET & PDGFR $\alpha / \beta$, VEGFR1, VEGFRs, KIT, FLT3, CSF1R, RET \\
\hline Temsirolimus & Advanced renal cell carcinoma & mTOR \\
\hline Tofacitinib & Rheumatoid arthritis & JAK1, JAK2 \\
\hline Trametinib & Melanoma and NSCLC with BRAF V600E mutation & $\mathrm{MEK} 1 / 2$ \\
\hline Vandentinib & Medullary thryoid carcinoma & EGFRs, RET, VEGFRs, TEK, EPHRs, SRC, BRK \\
\hline Vemurafenib & Melanoma with BRAF V600E mutation, Erdheim-Chester disease & BRAF, ARAF, CRAF, SRMS, ACK1, MAP4K5, FGR \\
\hline
\end{tabular}

A current (December 2017) list of kinase inhibitors approved for the treatment of various cancer types. Some of these targets are implicated in mCRPC; however, the kinase inhibitors assessed in clinical trials for MCRPC did not demonstrate sufficient response and were not approved.

ALL, acute lymphoblastic leukemia; CML, chronic myelogenous leukemia; CLL, chronic lymphocytic leukemia; GIST, gastrointestinal stroma tumor; MCL, mantle cell lymphoma; MCRPC, metastatic castration-resistant prostate cancer; mTOR, mammalian target of rapamycin; NSCLC, non-small-cell lung cancer; PNET, progressive neuroendocrine tumor of pancreatic origin; PV, polycythemia vera; RCC, renal cell carcinoma.

in combination with docetaxel was found to be safe in CRPC patients and resulted in more than $50 \%$ reduction in PSA levels (78). Another investigational mTOR inhibitor, ridaforolimus, in phase II trials in combination with bicalutamide showed a $30 \%$ decrease in PSA response (79).

SRC non-receptor tyrosine kinase is involved in multiple signaling pathways in PrCa including cell proliferation, migration, angiogenesis, survival, and transition to androgen-independent growth (80). Dasatinib is a SRC inhibitor that was shown to suppress cell proliferation of PrCa cell lines (81); inhibit cell adhesion, migration, and invasion (82); and reduce tumor growth in a mouse xenograft model (83). In a phase II clinical trial, dasatinib had a definite but limited activity in advanced mCRPC but was poorly tolerated, and $43 \%$ of patients discontinued treatment due to toxicity (84). In a previous phase II clinical trial, dasatinib did not show significant PSA response, and only $19 \%$ of men with mCRPC were free of disease progression at 6 months (85). In a separate phase II combination trial of dasatinib and 
docetaxel, it was observed that $41 \%$ of the participants showed a PSA response and $32 \%$ of patients with bone metastases showed improvement as assessed by bone scans (86). In a phase II clinical trial with single-agent saracatinib, another SRC inhibitor, only $18 \%$ of patients with $\mathrm{mCRPC}$ showed a reduction of $<30 \%$ in PSA (87). In a more recent phase II clinical trial, saracatinib was assessed in a subset of mCRPC patients who showed recurrence postdocetaxel treatment. Only $26 \%$ of patients had stable disease after 8 weeks with the remaining patients showing expansion of existing lesions. Fatigue was reported in $25 \%$ of patients, and this study was discontinued as it could not be determined if saracatinib would inhibit metastasis (88). Another phase II study of a SRC inhibitor, KX2-391, was closed due to prespecified futility rule and toxicities (89).

A plethora of kinase inhibitors have been assessed in phase I and phase II trials for patients with mCRPC. These include single agents such as sorafenib (74), sunitinib (90), cabozantinib (91), dasatinib (85), lapatinib (92), imatinib (93), and gefitinib (94) as well as erlotinib (95) and dasatinib (96) in combination with docetaxel. None of these agents demonstrated sufficient response or activity to advance to phase III trials, with the exception of cabozantinib and dasatinib (Table 3). Unfortunately, neither of these two inhibitors demonstrated significant overall improved survival benefits in those phase III trials $(85,91)$.

Most of the kinase inhibitors that entered clinical trials for mCRPC have been discontinued due to low efficacy even though they have been approved for treatment in other cancer types. This emphasizes the complexity and lack of any one dominant kinase driving the biology in $\mathrm{MCRPC}$, affecting the response of any one targeted therapy in an unselected patient population. The challenge is to develop clinical trials based on biomarkers that can categorize a patient's cancer subtype to any one of several FDA-approved targeted therapies, similar to the NCI-MATCH

TABLE 3 | Kinase inhibitors that have been assessed in clinical trials for $m$ CRPC.

\begin{tabular}{lllll}
\hline $\begin{array}{l}\text { Kinase } \\
\text { inhibitors }\end{array}$ & Target & Approved? & $\begin{array}{l}\text { Phase } \\
\text { reached }\end{array}$ & Reference \\
\hline Cabozantinib & VEGFR, & No & $\|$ & Smith et al. (91) \\
& MET & & & \\
Cediranib & VEGFR & No & $\|$ & Dahut et al. (97) \\
Dasatinib & SRC & No & $\|$ & Araujo et al. (96) \\
Dasatinib & SRC & No & $\|$ & Yu et al. (85) \\
Erlotinib & EGFR & No & $\|$ & Gross et al. (95) \\
Gefitinib & EGFR & No & $\|$ & Canil et al. (94) \\
Imatinib & ABL & No & $\|$ & Lin et al. (93) \\
Lapatinib & EGFR, & No & $\|$ & Whang et al. (92) \\
& HER2 & & & Lara et al. (87) \\
Saracatinib & SRC & No & $\|$ & Posadas et al. (88) \\
Saracatinib & FYN & No & $\|$ & Aragon-Ching et al. (74) \\
Sorafenib & PDGFR, & No & $\|$ & Dror Michaelson et al. (90) \\
Sunitinib & VEGFR & & &
\end{tabular}

Food and Drug Administration approved kinase inhibitors assessed in early phase I and II clinical trials for metastatic castration-resistant prostate cancer did not demonstrate sufficient response or activity to advance to phase III trials, with the exception of cabozantinib and dasatinib. However, neither inhibitor demonstrated significant overall survival benefits and both were not approved. trials, but for protein activity. To date, only eight PrCa patients have been "matched" to any given targeted therapy in the NCIMATCH trial (NCI Formulary, May 8, 2017). This reveals a couple concerns about implementing targeted therapies in mCRPC: (1) the paucity of activating mutations as assessed by genomic panels eliminates a majority of CRPC patients from selected targeted therapies and (2) even if the mutation is observed, information on the activity of that protein is missing. To that point, selection of a targeted agent by mutation information alone, independent of tissue type may also be misleading. Key evidence from colon cancer suggests that BRAF (V600E)-mutant tumors are not responsive to vemurafenib alone but only in combination with an EGFR inhibitor to repress the rapid feedback activation of EGFR by vemurafenib treatment (98). This example suggests that to observe prolonged, clinically significant benefits to patients with mCRPC (or other cancer types), we need to begin designing trials that not only assess the genomic aspects of the tumor but also the feedback regulation. If we can do this, we might have a better chance of inhibiting resistance and prolonging survival.

While disappointing, these clinical trial results do not mean that agents used in these failed clinical trials will not have a future role in mCRPC treatment. It is postulated that select kinase inhibitors used in combination with other targeted agents such as second-generation hormonal therapies (abiraterone acetate and enzalutamide) or checkpoint inhibitor immunotherapies may provide substantial clinical benefit. We are only starting to understand the mechanism of action of these kinase inhibitors in the tumor microenvironment and on immune cells. As this becomes clearer, we can move forward with more rationale combination treatments.

\section{PROTEOMICS AND PHOSPHOPROTEOMICS IN OTHER CANCERS}

\section{Ovarian Cancer}

In an effort to characterize the genome and proteome of highgrade serous ovarian cancer, Zhang et al. performed MS-based proteomic analysis on 174 ovarian tumors (169 high grade) previously characterized by The Cancer Genome Atlas (TCGA) (99). The integration of genomic and proteomic data showed an $80 \%$ positive correlation between mRNA and protein abundance with metabolic pathways and interferon response being more highly correlated than stable, abundant proteins consisting of housekeeping genes. Unbiased clustering using protein abundance data grouped tumors into mesenchymal, proliferative, immunoreactive, and differentiated subtypes, as previously defined by the TCGA transcriptome analysis. However, there was a fifth cluster of tumor-enriched proteins related to extracellular matrix interactions and erythroid and platelet functions that were not identified by genomic data alone. Interestingly, increased protein phosphorylation in high-grade serous ovarian cancer samples suggested that multiple pathways may be activated in these tumors. Indeed, the PDGFR signaling pathway important for angiogenesis, the RHOA regulatory and integrin-linked kinase pathway associated with invasion and cell mobility, and pathways 
associated with chemokine signaling and adaptive immune response were observed to be activated explaining the aggressive nature of this disease. In patients with activated PDGFR, for example, stratification and enrollment of patients with expected short overall survival into antiangiogenic clinical trial therapies will be beneficial. A phase II clinical trial to determine the effectiveness of imatinib, a PDGFR and KIT inhibitor, in patients with refractory ovarian cancer has been completed (NCT00039585) with no results posted to date. However, it might be promising as imatinib has been shown to be effective to inhibit the growth of ovarian cancer cells in a PDGFR-specific manner by arresting cells at the G0-G1 phase and preventing progression through the $S$ phase (100). Other multifunctional kinase inhibitors that may be effective therapeutic agents for ovarian cancer include pazopanib (targets VEGFR, PDGFR, FGFR, and KIT), sunitinib (targets VEGFR, PDGFR, FLT3, and KIT), and sorafenib (targets VEGFR, PDGFR, and RAF kinases) (101). However, these agents did not do well in phase I and II clinical trials. With pazopanib, there was a 5.6-month progression-free survival and overall survival could not be determined because of toxicities and adverse effects (102). With sunitinib, an objective response rate of only $8.3 \%$ with a 9.9 -week progression-free survival reported (103). Sorafenib showed only $3.4 \%$ partial response, no progression-free survival, or overall survival advantage and low tolerability (104).

\section{Lung Cancer}

Previous work by Rikova et al. have analyzed 41 non-small-cell lung cancer cell lines and more than 150 tumors to identify and group samples based on the activated tyrosine kinases using phosphoproteomics (105). Robust phosphorylation was observed in known oncogenic kinases such as EGFR and c-MET, as well as novel (at the time) ALK and ROS fusion proteins (105). In addition, they identified activated tyrosine kinases not previously indicated in this disease such as PDGRR $\alpha$ and DDR1. PDGFR $\alpha$, which was found to be aberrantly activated in the H1703 cell line and also in eight tumor samples, was nominated as a novel therapeutic target. Investigating the sensitivity of $\mathrm{H} 1703$ cell line to imatinib (PDGFR inhibitor) and gefitinib (EGFR inhibitor) showed that phosphorylation of AKT at serine 473 was blocked by imatinib but not gefitinib. Cell lines negative for $\operatorname{PDGFR} \alpha$ were insensitive to imatinib, correlating kinase activity to drug sensitivity. A phase II clinical trial assessed the effectiveness of imatinib and docetaxel in patients with PDFGR expressing non-small-cell lung cancer but was terminated early due to high drug intolerance and no added clinical efficacy. The authors recommend that future studies with PDGFR inhibitors should include the measurement of PDGFR as a positive predictive biomarker prior to therapy administration (106).

Quantitative phosphoproteomics was performed on nonsmall-cell lung cancer tumors derived from multiple patients, and signaling networks that were known to be involved in lung cancer oncogenesis were identified (107). Activated kinases found in these tumor samples included ERBB2, c-Met, AKT, RAF, and PI3K and direct transcriptional regulators (MEF2D, TP53, ELK3, and ATF7).

\section{Breast Cancer}

Mertins et al. utilized quantitative MS-based proteomics and phosphoproteomics to analyze over 100 genomically characterized breast cancers (108). The samples represented four main mRNA-defined PAM50 breast cancer subtypes, namely basallike, luminal A, luminal B, and ERBB2-positive subtypes. Their results revealed a connection between loss of CETN3 and SKP1 to increased expression levels of EGFR and SKP1 loss to increased SRC levels (108). They also identified a G-protein couple receptor cluster that was not identified at the mRNA level. In addition, highly phosphorylated kinases identified included ERBB2, CDK12, PAK41, RIPK2, and TLK2. The proteome subtypes identified by using the global proteomics and phosphoproteomics data included basal-enriched, luminal-enriched, and stromalenriched, while ERBB2-enriched tumors were distributed among these three proteome subgroups (unlike with the clustering seen with the PAM50 genes, mRNA-defined subtypes). The basal and luminal groups showed a significant overlap between mRNA and proteome-defined subtypes, but the stromal-enriched proteome subgroup represented a mix of all mRNA-based subtypes. Pathway analyses showed that the luminal subtype was exclusively enriched for estradiol and ESR1-driven genes, while the basal proteome subtype was enriched for multiple gene sets including MYC target genes for cell cycle, checkpoint, and DNA repair pathway regulators including AURKA/B, ATM, ATR, CHEK1/2, and BRCA1/2 (108). This work has led to the identification of potential druggable kinases in breast cancer, other than ERBB2, and emphasized the advantage of connecting the genome to the proteome.

\section{Colorectal Cancer}

Zhang et al. analyzed the proteomes of colorectal tumors previously characterized by the TCGA (109). They showed that somatic variants were associated with lower protein abundance compared to germline variants and that mRNA expression did not predict protein abundance between tumors. Proteomics identified five subtypes in the TCGA cohort with two overlapping the transcriptomic subtype: microsatellite instability/CpG island methylation subtype. This demonstrated that proteomic data may enable prioritization of potential driver genes. They also showed that chromosome $20 \mathrm{q}$ amplicon was associated with high changes at the mRNA and protein levels, some of which included HNF4 $\alpha$, TOMM34, and SRC (109).

The data obtained from these integrative approaches provide a link from genotype to proteotype to phenotype to better understand the biology at the molecular level that lead to aggressive cancer. Insights gained from the studies mentioned above are evidence that MS-based phosphoproteomics and integration of proteomic and genomic data are advantageous for patient stratification, for identification of personalize therapies, and to understand mechanisms involved in resistance to standard treatment.

\section{HOW TO MEASURE PATHWAY ACTIVITY CLINICALLY: TARGETED MS}

Targeted phosphoproteomic technologies are rapidly rising as key tools for the identification and quantification of highly selected 
phosphopeptides in clinical samples (Figure 4). Some advantages of targeted MS are increased speed, sensitivity, reproducibility, and selectivity of your analyte. Targeted MS technology depends on the use of more expensive heavy-labeled synthetic custom phosphopeptides for assay development and absolute quantification (110-112). These phosphopeptides are designed to limit the focus to a specific subset of targets of interest, without large-scale biomarker screening, although the targets can be highly customizable.

Limited sample amount from biopsies is a major challenge for phosphoproteomic analyses clinically. The optimization of protocols to efficiently sample biopsy amounts coupled with enrichment techniques to reduce sample complexity for reliable and reproducible detection via targeted MS are being
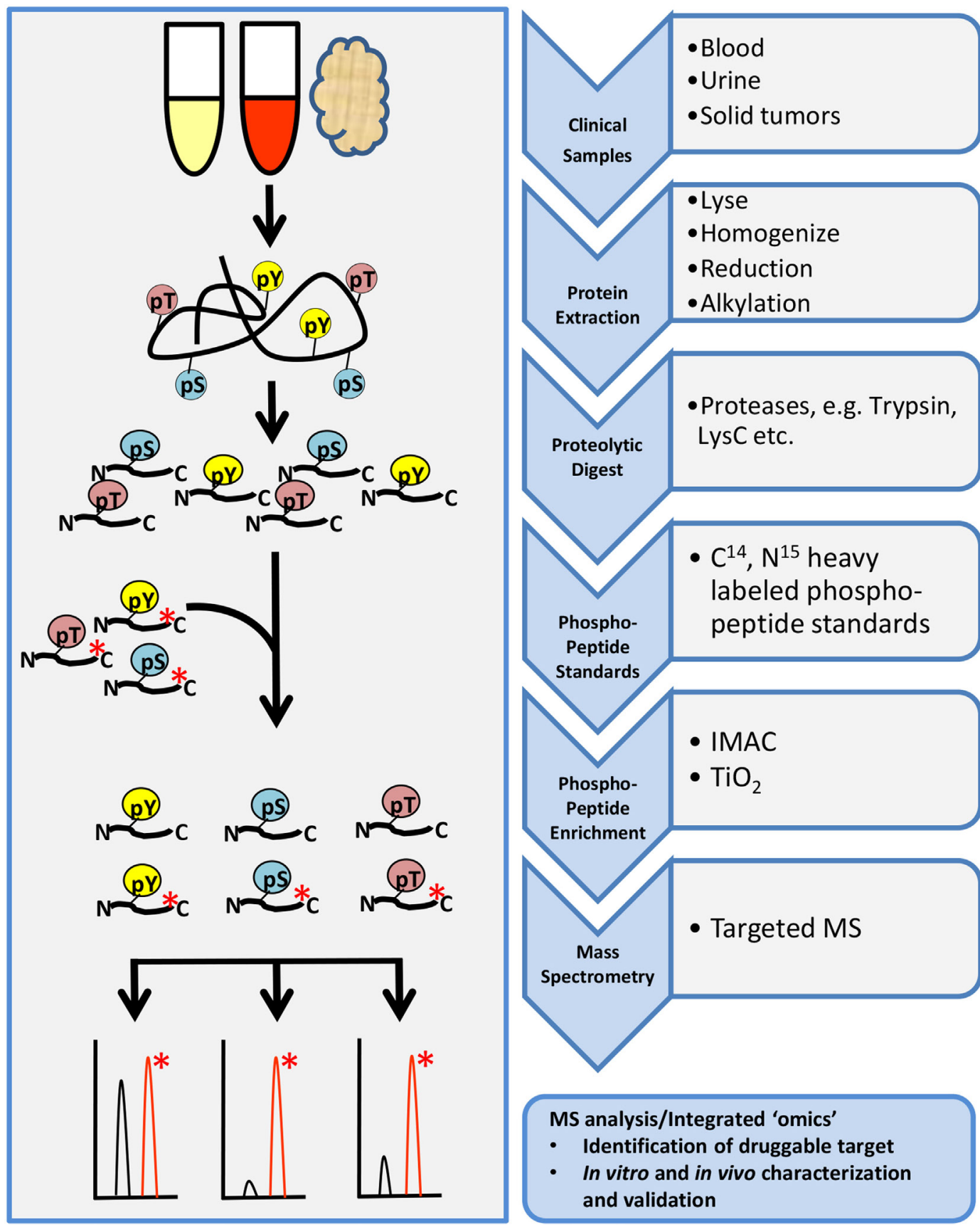

FIGURE 4 | General workflow for targeted phosphoproteomics analysis. Tissue samples may include cultures cell lines, mouse xenografts, or clinical biopsy specimens such as blood, urine, or tumor biopsies. Samples are processed as described in the shotgun workflow up to proteolytic digestion. Custom designed heavy-labeled peptide standards to specific targets of interest are spiked in with the tryptic peptides followed by enrichment and analysis by LC-MS/MS. 
investigated $(42,113)$. For example, a phosphoproteomic platform known as EasyPhos was shown to quantify thousands of phosphopeptides from only $1 \mathrm{mg}$ of cells or tissue protein rapidly in a 96-well format (114). In addition, integrating pressure cycling technology-assisted sample preparation and SWATH-MS allowed for consistent sample preparation reproducibility as well as the quantification of thousands of proteins from biopsy level tissues $(115,116)$. Shao et al. evaluated minimum sample requirements from 50,000 cultured cells and as low as $0.2-0.5 \mathrm{mg}$ of wet tissue weight and reported that these smaller sample sizes achieved high quantitative accuracy that were both reliable and reproducible (115). It is important to note that SWATH-MS was previously applied to the proteome and not the phosphoproteome, so other modifications to the protocol may be necessary. The capability of sample multiplexing using isobaric labeling allows the monitoring of up to 10 samples simultaneously in a single-targeted MS run, significantly reducing cost and run times (117). Overall, with significant improvements and advances in protocol optimization and sample procurement, targeted phosphoproteomic analyses will soon be a feasible and essential tool in the clinical setting for assessment of diagnostic, prognostic, or predictive biomarkers (118).

\section{SOURCES OF PATIENT MATERIAL FOR TARGETED MS ASSAYS}

A number of studies have applied proteomics on various biological systems including tissue, serum (119), urine (120), and cell lines and conditioned media from cultured cells (121). Frozen or formalin-fixed paraffin-embedded samples represent the two major processing protocols for collecting clinical tissues and targeted MS assays are capable to detect proteins or phosphoproteins from either source depending on the assay design. The major challenges with tissue-based approaches are small amounts (biopsies), and they are not conducive for sequential assessment of pathways related to disease progression or drug resistance. Since repeated metastatic tissue biopsies are not feasible, ethical, or safe to patients with mCRPC, assessing liquid biopsies, such as blood or urine, may be an effective substitute for biomarker or pathway evaluation studies over time. Some approaches include isolation of CTCs, cell-free DNA, or exosomes in patient blood or serum.

Cell-free DNA has the capability to detect novel mutations (or loss of a mutation) after treatment, indicative of therapy success or resistance. However, cell-free DNA will generate molecular characterization at the genomic level without any information at the protein level. Several great reviews have been written on cell-free DNA and will not be discussed further (122-124). Isolation of CTCs have also garnered much interest in the $\mathrm{PrCa}$ community since the finding that AR splice variants can serve as potential biomarkers of resistance to abiraterone acetate or enzalutamide (14). Currently, CTCs are primarily used for RNA or DNA-based analyses and protocols are being developed to investigate proteins. Indeed, a recent study by Scher et al. identified nuclear ARv7 protein in CTCs of patients with mCRPC as a biomarker for treatment selection (125). Importantly, patients with CTCs consisting of nuclear ARv7 were likely to have a better overall survival on taxane-based chemotherapy, suggesting that the assessment of ARv7 protein is critical for treatment selection. However, assessment of phosphoproteins in CTCs have not been reported and represents a big hurdle is the utilization of this technology to measure pathway activity. Furthermore, isolation of CTCs from blood is technically challenging and the number of CTCs in blood is quite low with counts ranging between 5 and 10 CTCs per $10 \mathrm{ml}$ of blood in patients with low number metastases (126), making this approach unlikely for targeted MS assays in the current form and more suitable for immunofluorescence at the single cell level. However, if we can evaluate signaling networks in CTCs using phosphosite-specific antibodies via immunofluorescence, we can gain a better understanding of the heterogeneity

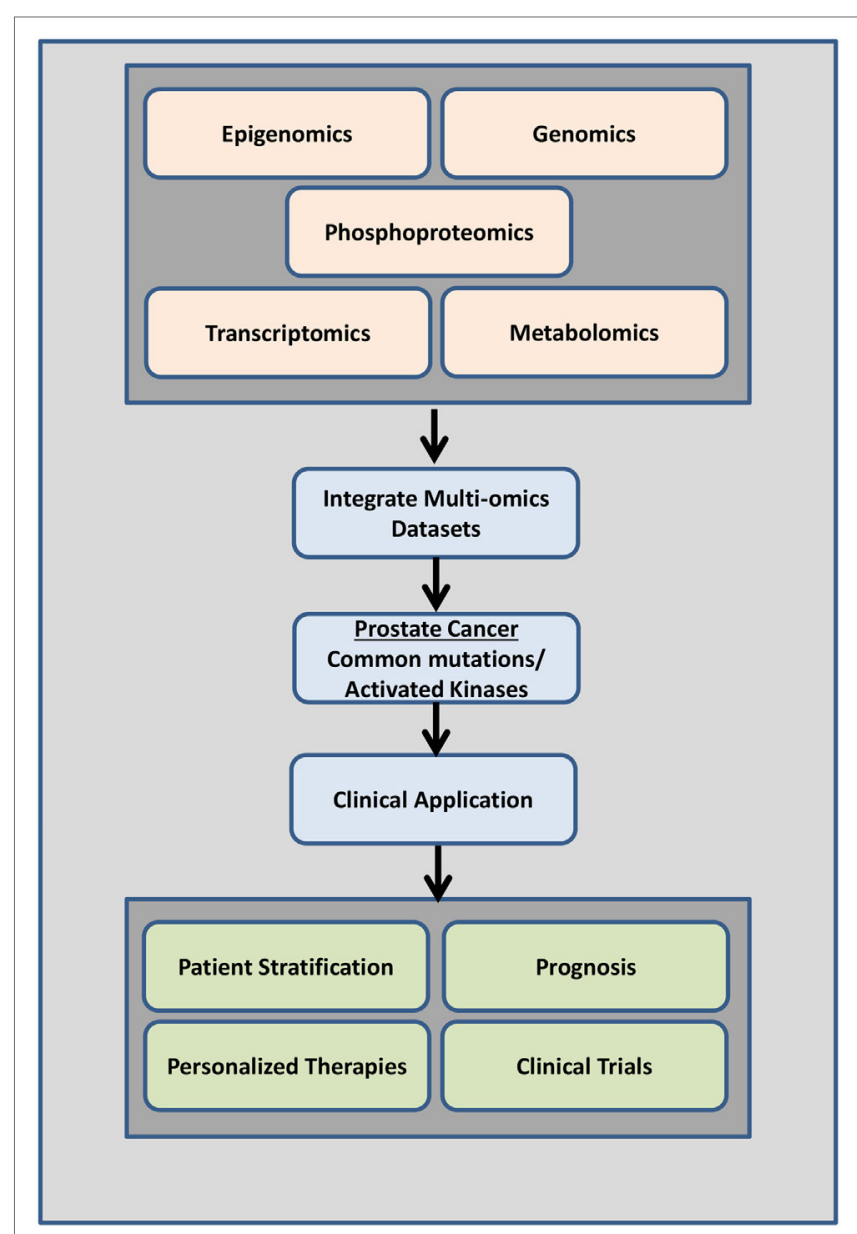

FIGURE 5 | Overview of data integration. Data from a combination of phosphoproteomics, genomics, transcriptomics epigenomics, and metabolomics studies investigating the mutational landscape,

phosphoproteomic signature, gene expression changes, and regulation in prostate cancer tumors of individual patients can be used clinically to determine disease drivers (mutations and/or activated kinases and aberrantly regulated signaling pathways) as diagnostic tools, to predict patient outcome, to design personalized therapeutic options, and to aid in better clinical trials design. 
of signaling in these cell types as well as identify possible new therapeutic targets for treatment.

An exciting new area in liquid biopsy research that has potential for MS-based assays is the isolation of extracellular vesicles or exosomes. Exosomes are an excellent source for biomarker discovery because the cargo they carry reflects the same genomic, transcriptomic, or proteomic information from parental cancer cells $(127,128)$. In a study where exosomes were isolated by ultracentrifugation from primary prostate epithelial and PrCa cell line supernatants, MS-based proteomic analysis revealed candidate biomarkers more abundant in PrCa cell lines, including FASN, XPO1, ALIX, and ENO1 (129). In a later MS-based study assessing the proteome of urinary exosomes, differential protein expression was observed between PrCa patients and healthy male controls (130). Some of these proteins included transmembrane protein 256 (TM256), LAMTOR, VATL, ADIRF, and RAB family. Claudin 3 was found in exosomes isolated from the plasma of patients with localized and mCRPC compared to patients with benign prostatic hyperplasia and healthy individuals (131). This demonstrated the benefits and potential clinical application of exosomes for the identification and validation of urine- and blood-based biomarkers in PrCa.

\section{CONCLUSION}

The majority of studies have predominantly focused on the genetic signatures of cancer identifying driver mutations that confer drug resistance. Given the low mutation rates in $\mathrm{PrCa}$ and mCRPC relative to other cancers strongly supports the need to identify other candidate biomarkers via proteomic or phosphoproteomic technologies. Systems biology approaches revealed that genomic and transcriptomic data alone may be missing key players regulating cellular function and disease (132). Integrating other "omics" data sets such as metabolomics, epigenomics,

\section{REFERENCES}

1. Nantermet PV, Xu J, Yu Y, Hodor P, Holder D, Adamski S, et al. Identification of genetic pathways activated by the androgen receptor during the induction of proliferation in the ventral prostate gland. J Biol Chem (2004) 279:1310-22. doi:10.1074/jbc.M310206200

2. Basch E, Oliver TK, Vickers A, Thompson I, Kantoff P, Parnes H, et al. Screening for prostate cancer with prostate-specific antigen testing: American Society of Clinical Oncology Provisional Clinical Opinion. J Clin Oncol (2012) 30:3020-5. doi:10.1200/JCO.2012.43.3441

3. Epstein JI, Zelefsky MJ, Sjoberg DD, Nelson JB, Egevad L, Magi-Galluzzi C, et al. A contemporary prostate cancer grading system: a validated alternative to the Gleason score. Eur Urol (2016) 69:428-35. doi:10.1016/j.eururo.2015. 06.046

4. Harris WP, Mostaghel EA, Nelson PS, Montgomery B. Androgen deprivation therapy: progress in understanding mechanisms of resistance and optimizing androgen depletion. Nat Clin Pract Urol (2009) 6:76-85. doi:10.1038/ ncpuro1296

5. Tangen CM, Faulkner JR, Crawford ED, Thompson IM, Hirano D, Eisenberger M, et al. Ten-year survival in patients with metastatic prostate cancer. Clin Prostate Cancer (2003) 2:41-5. doi:10.3816/CGC.2003.n.011

6. Fizazi K, Tran N, Fein L, Matsubara N, Rodriguez-Antolin A, Alekseev BY, et al. Abiraterone plus prednisone in metastatic, castration-sensitive prostate cancer. N Engl J Med (2017) 377:352-60. doi:10.1056/NEJMoa1704174 proteomics, and phosphoproteomics with genomic or gene expression data sets will reveal other key pathways, regulators, and complex signaling networks that may be involved in cell growth, proliferation, and cancer progression (Figure 5). This will give us a more comprehensive view into aberrantly regulated signaling pathways and will lead to the identification of key druggable regulators/molecules (Figure 5).

Our understanding of PrCa biology is rapidly increasing, as well as the availability and affordability of high-throughput technologies for comprehensive molecular characterization of $\mathrm{PrCa}$ and an individual's genetic and proteomic makeup. With our expanding knowledge of the key players contributing to $\mathrm{PrCa}$ progression and resistance to treatment, the future will provide endless possibilities for rational, personalized therapies. This can be accomplished based on the measured disease drivers (mutations and/or activated kinases and aberrantly regulated signaling pathways) via the integration of phosphoproteomic, genomic, and transcriptomic data sets. Continued advancement and development of proteomic and phosphoproteomic technologies will provide exciting new opportunities for molecularly targeted treatment of mCRPC.

\section{AUTHOR CONTRIBUTIONS}

JR, MS, and JD wrote the commentary. JR and JD prepared and edited the figures.

\section{FUNDING}

We thank members of the Drake lab for advice and input. JD is supported by the Department of Defense Prostate Cancer Research Program W81XWH-15-1-0236, Prostate Cancer Foundation Young Investigator Award, the New Jersey Health Foundation, and a Precision Medicine Initiative Pilot Award from the Rutgers Cancer Institute of New Jersey.

7. James ND, de Bono JS, Spears MR, Clarke NW, Mason MD, Dearnaley DP, et al. Abiraterone for prostate cancer not previously treated with hormone therapy. N Engl J Med (2017) 377:338-51. doi:10.1056/NEJMoa1702900

8. O’Donnell A, Judson I, Dowsett M, Raynaud F, Dearnaley D, Mason M, et al. Hormonal impact of the 17alpha-hydroxylase/C(17,20)-lyase inhibitor abiraterone acetate (CB7630) in patients with prostate cancer. Br J Cancer (2004) 90:2317-25. doi:10.1038/sj.bjc.6601879

9. Sweeney CJ, Chen YH, Carducci M, Liu G, Jarrard DF, Eisenberger M, et al. Chemohormonal therapy in metastatic hormone-sensitive prostate cancer. N Engl J Med (2015) 373:737-46. doi:10.1056/NEJMoa1503747

10. Marques RB, Dits NF, Erkens-Schulze S, van Weerden WM, Jenster G. Bypass mechanisms of the androgen receptor pathway in therapy-resistant prostate cancer cell models. PLoS One (2010) 5:e13500. doi:10.1371/journal. pone. 0013500

11. Scher HI, Fizazi K, Saad F, Taplin ME, Sternberg CN, Miller K, et al. Increased survival with enzalutamide in prostate cancer after chemotherapy. $N$ Engl J Med (2012) 367:1187-97. doi:10.1056/NEJMoa1207506

12. Antonarakis ES, Lu C, Wang H, Luber B, Nakazawa M, Roeser JC, et al. AR-V7 and resistance to enzalutamide and abiraterone in prostate cancer. $N$ Engl J Med (2014) 371:1028-38. doi:10.1056/NEJMoa1315815

13. Guo Z, Yang X, Sun F, Jiang R, Linn DE, Chen H, et al. A novel androgen receptor splice variant is up-regulated during prostate cancer progression and promotes androgen depletion-resistant growth. Cancer Res (2009) 69:2305-13. doi:10.1158/0008-5472.CAN-08-3795 
14. Antonarakis ES, Lu C, Luber B, Wang H, Chen Y, Zhu Y, et al. Clinical significance of androgen receptor splice variant-7 mRNA detection in circulating tumor cells of men with metastatic castration-resistant prostate cancer treated with first- and second-line abiraterone and enzalutamide. J Clin Oncol (2017) 35:2149-56. doi:10.1200/JCO.2016.70.1961

15. Bluemn EG, Coleman IM, Lucas JM, Coleman RT, Hernandez-Lopez S, Tharakan R, et al. Androgen receptor pathway-independent prostate cancer is sustained through FGF signaling. Cancer Cell (2017) 32:474.e-89.e. doi:10.1016/j.ccell.2017.09.003

16. Aparicio A, Tzelepi V. Neuroendocrine (small-cell) carcinomas: why they teach us essential lessons about prostate cancer. Oncology (Williston Park) (2014) 28:831-8.

17. Beltran H, Tomlins S, Aparicio A, Arora V, Rickman D, Ayala G, et al. Aggressive variants of castration-resistant prostate cancer. Clin Cancer Res (2014) 20:2846-50. doi:10.1158/1078-0432.CCR-13-3309

18. Vlachostergios PJ, Puca L, Beltran H. Emerging variants of castration-resistant prostate cancer. Curr Oncol Rep (2017) 19:32. doi:10.1007/s11912-017-0593-6

19. Beltran H, Rickman DS, Park K, Chae SS, Sboner A, MacDonald TY, et al. Molecular characterization of neuroendocrine prostate cancer and identification of new drug targets. Cancer Discov (2011) 1:487-95. doi:10.1158/21598290.CD-11-0130

20. Tan HL, Sood A, Rahimi HA, Wang W, Gupta N, Hicks J, et al. Rb loss is characteristic of prostatic small cell neuroendocrine carcinoma. Clin Cancer Res (2014) 20:890-903. doi:10.1158/1078-0432.CCR-13-1982

21. Lee JK, Phillips JW, Smith BA, Park JW, Stoyanova T, McCaffrey EF, et al. $\mathrm{N}$-Myc drives neuroendocrine prostate cancer initiated from human prostate epithelial cells. Cancer Cell (2016) 29:536-47. doi:10.1016/j.ccell.2016. 03.001

22. Robinson D, Van Allen EM, Wu YM, Schultz N, Lonigro RJ, Mosquera JM, et al. Integrative clinical genomics of advanced prostate cancer. Cell (2015) 161:1215-28. doi:10.1016/j.cell.2015.05.001

23. Grasso CS, Wu YM, Robinson DR, Cao X, Dhanasekaran SM, Khan AP, et al. The mutational landscape of lethal castration-resistant prostate cancer. Nature (2012) 487:239-43. doi:10.1038/nature11125

24. Barbieri CE, Baca SC, Lawrence MS, Demichelis F, Blattner M, Theurillat JP, et al. Exome sequencing identifies recurrent SPOP, FOXA1 and MED12 mutations in prostate cancer. Nat Genet (2012) 44:685-9. doi:10.1038/ng.2279

25. Toren P, Zoubeidi A. Targeting the PI3K/Akt pathway in prostate cancer: challenges and opportunities (review). Int J Oncol (2014) 45:1793-801. doi:10.3892/ijo.2014.2601

26. Blattner M, Liu D, Robinson BD, Huang D, Poliakov A, Gao D, et al. SPOP mutation drives prostate tumorigenesis in vivo through coordinate regulation of PI3K/mTOR and AR signaling. Cancer Cell (2017) 31:436-51. doi:10.1016/j. ccell.2017.02.004

27. Pritchard CC, Mateo J, Walsh MF, De Sarkar N, Abida W, Beltran H, et al. Inherited DNA-repair gene mutations in men with metastatic prostate cancer. N Engl J Med (2016) 375:443-53. doi:10.1056/NEJMoa1603144

28. Goodall J, Mateo J, Yuan W, Mossop H, Porta N, Miranda S, et al. Circulating cell-free DNA to guide prostate cancer treatment with PARP inhibition. Cancer Discov (2017) 7:1006-17. doi:10.1158/2159-8290.CD-17-0261

29. Fong PC, Boss DS, Yap TA, Tutt A, Wu P, Mergui-Roelvink M, et al. Inhibition of poly(ADP-ribose) polymerase in tumors from BRCA mutation carriers. N Engl J Med (2009) 361:123-34. doi:10.1056/NEJMoa0900212

30. Mateo J, Carreira S, Sandhu S, Miranda S, Mossop H, Perez-Lopez R, et al. DNA-repair defects and olaparib in metastatic prostate cancer. $N$ Engl J Med (2015) 373:1697-708. doi:10.1056/NEJMoa1506859

31. Chatterjee P, Choudhary GS, Sharma A, Singh K, Heston WD, Ciezki J, et al. PARP inhibition sensitizes to low dose-rate radiation TMPRSS2-ERG fusion gene-expressing and PTEN-deficient prostate cancer cells. PLoS One (2013) 8:e60408. doi:10.1371/journal.pone.0060408

32. Kajanne R, Miettinen P, Tenhunen M, Leppa S. Transcription factor AP-1 promotes growth and radioresistance in prostate cancer cells. Int J Oncol (2009) 35:1175-82. doi:10.3892/ijo_00000434

33. Lavery A, Gilson C, Chowdhury S. PARP inhibitors and stratified treatment of prostate cancer. Expert Rev Anticancer Ther (2016) 16:1213-5. doi:10.1080/ 14737140.2016 .1243474

34. Leite KR, Srougi M, Sanudo A, Dall'Oglio MF, Nesrallah A, Antunes AA, et al. The use of immunohistochemistry for diagnosis of prostate cancer. Int Braz J Urol (2010) 36:583-90. doi:10.1590/\$1677-55382010000500008
35. Duraiyan J, Govindarajan R, Kaliyappan K, Palanisamy M. Applications of immunohistochemistry. J Pharm Bioallied Sci (2012) 4:S307-9. doi:10.4103/ 0975-7406.100281

36. Grubb RL, Calvert VS, Wulkuhle JD, Paweletz CP, Linehan WM, Phillips JL, et al. Signal pathway profiling of prostate cancer using reverse phase protein arrays. Proteomics (2003) 3:2142-6. doi:10.1002/pmic.200300598

37. Negm OH, Muftah AA, Aleskandarany MA, Hamed MR, Ahmad DA, Nolan CC, et al. Clinical utility of reverse phase protein array for molecular classification of breast cancer. Breast Cancer Res Treat (2016) 155:25-35. doi:10.1007/ s10549-015-3654-2

38. Giansanti P, Tsiatsiani L, Low TY, Heck AJ. Six alternative proteases for mass spectrometry-based proteomics beyond trypsin. Nat Protoc (2016) 11:993-1006. doi:10.1038/nprot.2016.057

39. Cohen P. The origins of protein phosphorylation. Nat Cell Biol (2002) 4:E127-30. doi:10.1038/ncb0502-e127

40. Sharma K, D'Souza RC, Tyanova S, Schaab C, Wiśniewski JR, Cox J, et al. Ultradeep human phosphoproteome reveals a distinct regulatory nature of Tyr and Ser/Thr-based signaling. Cell Rep (2014) 8:1583-94. doi:10.1016/j. celrep.2014.07.036

41. Olsen JV, Blagoev B, Gnad F, Macek B, Kumar C, Mortensen P, et al. Global, in vivo, and site-specific phosphorylation dynamics in signaling networks. Cell (2006) 127:635-48. doi:10.1016/j.cell.2006.09.026

42. Ong SE, Blagoev B, Kratchmarova I, Kristensen DB, Steen H, Pandey A, et al. Stable isotope labeling by amino acids in cell culture, SILAC, as a simple and accurate approach to expression proteomics. Mol Cell Proteomics (2002) 1:376-86. doi:10.1074/mcp.M200025-MCP200

43. Rush J, Moritz A, Lee KA, Guo A, Goss VL, Spek EJ, et al. Immunoaffinity profiling of tyrosine phosphorylation in cancer cells. Nat Biotechnol (2005) 23:94-101. doi:10.1038/nbt1046

44. Lazar C, Gatto L, Ferro M, Bruley C, Burger T. Accounting for the multiple natures of missing values in label-free quantitative proteomics data sets to compare imputation strategies. J Proteome Res (2016) 15:1116-25. doi:10.1021/ acs.jproteome.5b00981

45. Cox J, Mann M. MaxQuant enables high peptide identification rates, individualized p.p.b.-range mass accuracies and proteome-wide protein quantification. Nat Biotechnol (2008) 26:1367-72. doi:10.1038/nbt.1511

46. MacLean B, Tomazela DM, Shulman N, Chambers M, Finney GL, Frewen B, et al. Skyline: an open source document editor for creating and analyzing targeted proteomics experiments. Bioinformatics (2010) 26:966-8. doi:10.1093/ bioinformatics/btq054

47. Casado P, Rodriguez-Prados JC, Cosulich SC, Guichard S, Vanhaesebroeck B, Joel S, et al. Kinase-substrate enrichment analysis provides insights into the heterogeneity of signaling pathway activation in leukemia cells. Sci Signal (2013) 6:rs6. doi:10.1126/scisignal.2003573

48. Drake JM, Paull EO, Graham NA, Lee JK, Smith BA, Titz B, et al. Phosphoproteome integration reveals patient-specific networks in prostate cancer. Cell (2016) 166:1041-54. doi:10.1016/j.cell.2016.07.007

49. Tyanova S, Temu T, Carlson A, Sinitcyn P, Mann M, Cox J. Visualization of LC-MS/MS proteomics data in MaxQuant. Proteomics (2015) 15:1453-6. doi:10.1002/pmic.201400449

50. Pino LK, Searle BC, Bollinger JG, Nunn B, MacLean B, MacCoss MJ. The Skyline ecosystem: informatics for quantitative mass spectrometry proteomics. Mass Spectrom Rev (2017) 1-16. doi:10.1002/mas.21540

51. Drake JM, Graham NA, Stoyanova T, Sedghi A, Goldstein AS, Cai H, et al. Oncogene-specific activation of tyrosine kinase networks during prostate cancer progression. Proc Natl Acad Sci U S A (2012) 109:1643-8. doi:10.1073/ pnas. 1120985109

52. Drake JM, Graham NA, Lee JK, Stoyanova T, Faltermeier CM, Sud S, et al. Metastatic castration-resistant prostate cancer reveals intrapatient similarity and interpatient heterogeneity of therapeutic kinase targets. Proc Natl Acad Sci U S A (2013) 110:E4762-9. doi:10.1073/pnas.1319948110

53. Paull EO, Carlin DE, Niepel M, Sorger PK, Haussler D, Stuart JM. Discovering causal pathways linking genomic events to transcriptional states using tied diffusion through interacting events (TieDIE). Bioinformatics (2013) 29:2757-64. doi:10.1093/bioinformatics/btt471

54. Faltermeier CM, Drake JM, Clark PM, Smith BA, Zong Y, Volpe C, et al. Functional screen identifies kinases driving prostate cancer visceral and bone metastasis. Proc Natl Acad Sci U S A (2016) 113:E172-81. doi:10.1073/ pnas. 1521674112 
55. Lee BY, Hochgräfe F, Lin HM, Castillo L, Wu J, Raftery MJ, et al. Phosphoproteomic profiling identifies focal adhesion kinase as a mediator of docetaxel resistance in castrate-resistant prostate cancer. Mol Cancer Ther (2014) 13:190-201. doi:10.1158/1535-7163.MCT-13-0225-T

56. Jiang N, Hjorth-Jensen K, Hekmat O, Iglesias-Gato D, Kruse T, Wang C, et al. In vivo quantitative phosphoproteomic profiling identifies novel regulators of castration-resistant prostate cancer growth. Oncogene (2015) 34:2764-76. doi:10.1038/onc.2014.206

57. Ino $\mathrm{Y}$, Arakawa $\mathrm{N}$, Ishiguro $\mathrm{H}$, Uemura $\mathrm{H}$, Kubota $\mathrm{Y}$, Hirano $\mathrm{H}$, et al. Phosphoproteome analysis demonstrates the potential role of THRAP3 phosphorylation in androgen-independent prostate cancer cell growth. Proteomics (2016) 16:1069-78. doi:10.1002/pmic.201500365

58. Giorgianni F, Zhao Y, Desiderio DM, Beranova-Giorgianni S. Toward a global characterization of the phosphoproteome in prostate cancer cells: identification of phosphoproteins in the LNCaP cell line. Electrophoresis (2007) 28:2027-34. doi:10.1002/elps.200600782

59. Chen L, Giorgianni F, Beranova-Giorgianni S. Characterization of the phosphoproteome in LNCaP prostate cancer cells by in-gel isoelectric focusing and tandem mass spectrometry. J Proteome Res (2010) 9:174-8. doi:10.1021/pr900338q

60. Myung JK, Sadar MD. Large scale phosphoproteome analysis of LNCaP human prostate cancer cells. Mol Biosyst (2012) 8:2174-82. doi:10.1039/c2mb25151e

61. Watson K, Wang C, Yilmaz A, Bismar TA, Trpkov K. Use of immunohistochemistry in routine workup of prostate needle biopsies: a tertiary academic institution experience. Arch Pathol Lab Med (2013) 137:541-5. doi:10.5858/ arpa.2012-0145-OA

62. Martin NE, Gerke T, Sinnott JA, Stack EC, Andrén O, Andersson SO, et al. Measuring PI3K activation: clinicopathologic, immunohistochemical, and RNA expression analysis in prostate cancer. Mol Cancer Res (2015) 13:1431-40. doi:10.1158/1541-7786.MCR-14-0569

63. Rizzardi AE, Zhang X, Vogel RI, Kolb S, Geybels MS, Leung Y-K, et al. Quantitative comparison and reproducibility of pathologist scoring and digital image analysis of estrogen receptor beta2 immunohistochemistry in prostate cancer. Diagn Pathol (2016) 11:63. doi:10.1186/s13000-016-0511-5

64. Miller JC, Zhou H, Kwekel J, Cavallo R, Burke J, Butler EB, et al. Antibody microarray profiling of human prostate cancer sera: antibody screening and identification of potential biomarkers. Proteomics (2003) 3:56-63. doi:10.1002/ pmic. 200390009

65. Cancer Genome Atlas Research Network. The molecular taxonomy of primary prostate cancer. Cell (2015) 163:1011-25. doi:10.1016/j.cell.2015.10.025

66. Pin E, Stratton S, Belluco C, Liotta L, Nagle R, Hodge KA, et al. A pilot study exploring the molecular architecture of the tumor microenvironment in human prostate cancer using laser capture microdissection and reverse phase protein microarray. Mol Oncol (2016) 10:1585-94. doi:10.1016/j. molonc.2016.09.007

67. Taylor BS, Schultz N, Hieronymus H, Gopalan A, Xiao Y, Carver BS, et al. Integrative genomic profiling of human prostate cancer. Cancer Cell (2010) 18:11-22. doi:10.1016/j.ccr.2010.05.026

68. Beltran H, Prandi D, Mosquera JM, Benelli M, Puca L, Cyrta J, et al. Divergent clonal evolution of castration-resistant neuroendocrine prostate cancer. Nat Med (2016) 22:298-305. doi:10.1038/nm.4045

69. Kumar A, Coleman I, Morrissey C, Zhang X, True LD, Gulati R, et al. Substantial interindividual and limited intraindividual genomic diversity among tumors from men with metastatic prostate cancer. Nat Med (2016) 22:369-78. doi:10.1038/nm.4053

70. Abida W, Armenia J, Gopalan A, Brennan R, Walsh M, Barron D, et al. Prospective genomic profiling of prostate cancer across disease states reveals germline and somatic alterations that may affect clinical decision making. JCO Precis Oncol (2017):2017. doi:10.1200/PO.17.00029

71. Cerami E, Gao J, Dogrusoz U, Gross BE, Sumer SO, Aksoy BA, et al. The cBio cancer genomics portal: an open platform for exploring multidimensional cancer genomics data. Cancer Discov (2012) 2:401-4. doi:10.1158/2159-8290. CD-12-0095

72. Gao J, Aksoy BA, Dogrusoz U, Dresdner G, Gross B, Sumer SO, et al. Integrative analysis of complex cancer genomics and clinical profiles using the cBioPortal. Sci Signal (2013) 6:11. doi:10.1126/scisignal.2004088

73. Kelly WK, Halabi S, Carducci M, George D, Mahoney JF, Stadler WM, et al. Randomized, double-blind, placebo-controlled phase III trial comparing docetaxel and prednisone with or without bevacizumab in men with metastatic castration-resistant prostate cancer: CALGB 90401. J Clin Oncol (2012) 30:1534-40. doi:10.1200/JCO.2011.39.4767

74. Aragon-Ching JB, Jain L, Gulley JL, Arlen PM, Wright JJ, Steinberg SM, et al. Final analysis of a phase II trial using sorafenib for metastatic castration-resistant prostate cancer. BJU Int (2009) 103:1636-40. doi:10.1111/ j.1464-410X.2008.08327.x

75. Sonpavde G, Periman PO, Bernold D, Weckstein D, Fleming MT, Galsky MD, et al. Sunitinib malate for metastatic castration-resistant prostate cancer following docetaxel-based chemotherapy. Ann Oncol (2010) 21:319-24. doi:10.1093/ annonc/mdp323

76. Figlin RA, Brown E, Armstrong AJ, Akerley W, Benson AB 3rd, Burstein HJ, et al. NCCN task force report: mTOR inhibition in solid tumors. J Natl Compr Canc Netw (2008) 6(Suppl 5):S1-20.

77. Morgan TM, Pitts TE, Gross TS, Poliachik SL, Vessella RL, Corey E. RAD001 (Everolimus) inhibits growth of prostate cancer in the bone and the inhibitory effects are increased by combination with docetaxel and zoledronic acid. Prostate (2008) 68:861-71. doi:10.1002/pros.20752

78. Courtney KD, Manola JB, Elfiky AA, Ross R, Oh WK, Yap JT, et al. A phase I study of everolimus and docetaxel in patients with castration-resistant prostate cancer. Clin Genitourin Cancer (2015) 13:113-23. doi:10.1016/j. clgc.2014.08.007

79. Rizzieri DA, Feldman E, Dipersio JF, Gabrail N, Stock W, Strair R, et al. A phase 2 clinical trial of deforolimus (AP23573, MK-8669), a novel mammalian target of rapamycin inhibitor, in patients with relapsed or refractory hematologic malignancies. Clin Cancer Res (2008) 14:2756-62. doi:10.1158/1078-0432. CCR-07-1372

80. Wheeler DL, Iida M, Dunn EF. The role of Src in solid tumors. Oncologist (2009) 14:667-78. doi:10.1634/theoncologist.2009-0009

81. Lombardo LJ, Lee FY, Chen P, Norris D, Barrish JC, Behnia K, et al. Discovery of N-(2-chloro-6-methyl- phenyl)-2-(6-(4-(2-hydroxyethyl)-piperazin-1yl)-2-methylpyrimidin-4-ylamino)thiazole-5-carboxamide (BMS-354825), a dual Src/Abl kinase inhibitor with potent antitumor activity in preclinical assays. J Med Chem (2004) 47:6658-61. doi:10.1021/jm049486a

82. Nam S, Kim D, Cheng JQ, Zhang S, Lee JH, et al. Action of the Src family kinase inhibitor, dasatinib (BMS-354825), on human prostate cancer cells. Cancer Res (2005) 65:9185-9. doi:10.1158/0008-5472.CAN-05-1731

83. Park SI, Zhang J, Phillips KA, Araujo JC, Najjar AM, Volgin AY, et al. Targeting SRC family kinases inhibits growth and lymph node metastases of prostate cancer in an orthotopic nude mouse model. Cancer Res (2008) 68:3323-33. doi:10.1158/0008-5472.CAN-07-2997

84. Twardowski PW, Beumer JH, Chen CS, Kraft AS, Chatta GS, Mitsuhashi M, et al. A phase II trial of dasatinib in patients with metastatic castrationresistant prostate cancer treated previously with chemotherapy. Anticancer Drugs (2013) 24:743-53. doi:10.1097/CAD.0b013e328361feb0

85. Yu EY, Wilding G, Posadas E, Gross M, Culine S, Massard C, et al. Phase II study of dasatinib in patients with metastatic castration-resistant prostate cancer. Clin Cancer Res (2009) 15:7421-8. doi:10.1158/1078-0432.CCR09-1691

86. Araujo JC, Poblenz A, Corn P, Parikh NU, Starbuck MW, Thompson JT, et al. Dasatinib inhibits both osteoclast activation and prostate cancer PC-3-cellinduced osteoclast formation. Cancer Biol Ther (2009) 8:2153-9. doi:10.4161/ cbt.8.22.9770

87. Lara PN Jr, Longmate J, Evans CP, Quinn DI, Twardowski P, Chatta G, et al. A phase II trial of the Src-kinase inhibitor AZD0530 in patients with advanced castration-resistant prostate cancer: a California Cancer Consortium study. Anticancer Drugs (2009) 20:179-84. doi:10.1097/CAD.0b013e328325a867

88. Posadas EM, Ahmed RS, Karrison T, Szmulewitz RZ, O’Donnell PH, Wade JL 3rd, et al. Saracatinib as a metastasis inhibitor in metastatic castration-resistant prostate cancer: a University of Chicago Phase 2 Consortium and DOD/PCF Prostate Cancer Clinical Trials Consortium Study. Prostate (2016) 76:286-93. doi:10.1002/pros.23119

89. Antonarakis ES, Heath EI, Posadas EM, Yu EY, Harrison MR, Bruce JY, et al. A phase 2 study of KX2-391, an oral inhibitor of Src kinase and tubulin polymerization, in men with bone-metastatic castration-resistant prostate cancer. Cancer Chemother Pharmacol (2013) 71:883-92. doi:10.1007/ s00280-013-2079-z

90. Dror Michaelson M, Regan MM, Oh WK, Kaufman DS, Olivier K, Michaelson SZ, et al. Phase II study of sunitinib in men with advanced prostate cancer. Ann Oncol (2009) 20:913-20. doi:10.1093/annonc/mdp111 
91. Smith M, De Bono J, Sternberg C, Le Moulec S, Oudard S, De Giorgi U, et al. Phase III study of cabozantinib in previously treated metastatic castration-resistant prostate cancer: COMET-1. J Clin Oncol (2016) 34:3005-13. doi:10.1200/JCO.2015.65.5597

92. Whang YE, Armstrong AJ, Rathmell WK, Godley PA, Kim WY, Pruthi RS, et al. A phase II study of lapatinib, a dual EGFR and HER-2 tyrosine kinase inhibitor, in patients with castration-resistant prostate cancer. Urol Oncol (2013) 31:82-6. doi:10.1016/j.urolonc.2010.09.018

93. Lin AM, Rini BI, Weinberg V, Fong K, Ryan CJ, Rosenberg JE, et al. A phase II trial of imatinib mesylate in patients with biochemical relapse of prostate cancer after definitive local therapy. BJU Int (2006) 98:763-9. doi:10.1111/j.1464-410X.2006.06396.x

94. Canil CM, Moore MJ, Winquist E, Baetz T, Pollak M, Chi KN, et al. Randomized phase II study of two doses of gefitinib in hormone-refractory prostate cancer: a trial of the National Cancer Institute of Canada-Clinical Trials Group. J Clin Oncol (2005) 23:455-60. doi:10.1200/JCO.2005.02.129

95. Gross M, Higano C, Pantuck A, Castellanos O, Green E, Nguyen K, et al. A phase II trial of docetaxel and erlotinib as first-line therapy for elderly patients with androgen-independent prostate cancer. BMC Cancer (2007) 7:142. doi:10.1186/1471-2407-7-142

96. Araujo JC, Trudel GC, Saad F, Armstrong AJ, Yu EY, Bellmunt J, et al. Docetaxel and dasatinib or placebo in men with metastatic castrationresistant prostate cancer (READY): a randomised, double-blind phase 3 trial. Lancet Oncol (2013) 14:1307-16. doi:10.1016/S1470-2045(13)70479-0

97. Dahut WL, Madan RA, Karakunnel JJ, Adelberg D, Gulley JL, Turkbey IB, et al. Phase II clinical trial of cediranib in patients with metastatic castration-resistant prostate cancer. BJU International (2013) 111:1269-80. doi:10.1111/j.1464-410X.2012.11667.x

98. Prahallad A, Sun C, Huang S, Di Nicolantonio F, Salazar R, Zecchin D, et al. Unresponsiveness of colon cancer to BRAF(V600E) inhibition through feedback activation of EGFR. Nature (2012) 483:100-3. doi:10.1038/ nature 10868

99. Zhang H, Liu T, Zhang Z, Payne SH, Zhang B, McDermott JE, et al. Integrated proteogenomic characterization of human high-grade serous ovarian cancer. Cell (2016) 166:755-65. doi:10.1016/j.cell.2016.05.069

100. Matei D, Chang DD, Jeng MH. Imatinib mesylate (Gleevec) inhibits ovarian cancer cell growth through a mechanism dependent on platelet-derived growth factor receptor alpha and Akt inactivation. Clin Cancer Res (2004) 10:681-90. doi:10.1158/1078-0432.CCR-0754-03

101. Coward JI, Middleton K, Murphy F. New perspectives on targeted therapy in ovarian cancer. Int J Womens Health (2015) 7:189-203. doi:10.2147/IJWH. S52379

102. du Bois A, Floquet A, Kim JW, Rau J, del Campo JM, Friedlander M, et al. Incorporation of pazopanib in maintenance therapy of ovarian cancer. J Clin Oncol (2014) 32:3374-82. doi:10.1200/JCO.2014.55.7348

103. Campos SM, Penson RT, Matulonis U, Horowitz NS, Whalen C, Pereira L, et al. A phase II trial of Sunitinib malate in recurrent and refractory ovarian, fallopian tube and peritoneal carcinoma. Gynecol Oncol (2013) 128:215-20. doi:10.1016/j.ygyno.2012.07.126

104. Matei D, Sill MW, Lankes HA, DeGeest K, Bristow RE, Mutch D, et al. Activity of sorafenib in recurrent ovarian cancer and primary peritoneal carcinomatosis: a gynecologic oncology group trial. JClin Oncol (2011) 29:69-75. doi:10.1200/JCO.2009.26.7856

105. Rikova K, Guo A, Zeng Q, Possemato A, Yu J, Haack H, et al. Global survey of phosphotyrosine signaling identifies oncogenic kinases in lung cancer. Cell (2007) 131:1190-203. doi:10.1016/j.cell.2007.11.025

106. Tsao AS, Liu S, Fujimoto J, Wistuba II, Lee JJ, Marom EM, et al. Phase II trials of imatinib mesylate and docetaxel in patients with metastatic non-small cell lung cancer and head and neck squamous cell carcinoma. J Thorac Oncol (2011) 6:2104-11. doi:10.1097/JTO.0b013e31822e 7256

107. Schweppe DK, Rigas JR, Gerber SA. Quantitative phosphoproteomic profiling of human non-small cell lung cancer tumors. J Proteomics (2013) 91:286-96. doi:10.1016/j.jprot.2013.07.023

108. Mertins P, Mani DR, Ruggles KV, Gillette MA, Clauser KR, Wang P, et al. Proteogenomics connects somatic mutations to signalling in breast cancer. Nature (2016) 534:55-62. doi:10.1038/nature18003

109. Zhang B, Wang J, Wang X, Zhu J, Liu Q, Shi Z, et al. Proteogenomic characterization of human colon and rectal cancer. Nature (2014) 513:382-7. doi:10.1038/nature13438
110. Kettenbach AN, Rush J, Gerber SA. Absolute quantification of protein and post-translational modification abundance with stable isotopelabeled synthetic peptides. Nat Protoc (2011) 6:175-86. doi:10.1038/nprot. 2010.196

111. Gillette MA, Carr SA. Quantitative analysis of peptides and proteins in biomedicine by targeted mass spectrometry. Nat Methods (2013) 10:28-34. doi:10.1038/nmeth.2309

112. Whiteaker JR, Zhao L, Yan P, Ivey RG, Voytovich UJ, Moore HD, et al. Peptide immunoaffinity enrichment and targeted mass spectrometry enables multiplex, quantitative pharmacodynamic studies of phosphosignaling. Mol Cell Proteomics (2015) 14:2261-73. doi:10.1074/mcp.O115. 050351

113. Dunn JD, Reid GE, Bruening ML. Techniques for phosphopeptide enrichment prior to analysis by mass spectrometry. Mass Spectrom Rev (2010) 29:29-54. doi:10.1002/mas.20219

114. Humphrey SJ, Azimifar SB, Mann M. High-throughput phosphoproteomics reveals in vivo insulin signaling dynamics. Nat Biotechnol (2015) 33:990-5. doi:10.1038/nbt.3327

115. Shao S, Guo T, Koh CC, Gillessen S, Joerger M, Jochum W, et al. Minimal sample requirement for highly multiplexed protein quantification in cell lines and tissues by PCT-SWATH mass spectrometry. Proteomics (2015) 15:3711-21. doi:10.1002/pmic.201500161

116. Zhu Y, Guo T. High-throughput proteomic analysis of fresh-frozen biopsy tissue samples using pressure cycling technology coupled with SWATH mass spectrometry. Methods Mol Biol (2017) 1-9. doi:10.1007/7651_2017_87

117. Erickson BK, Rose CM, Braun CR, Erickson AR, Knott J, McAlister GC, et al. A strategy to combine sample multiplexing with targeted proteomics assays for high-throughput protein signature characterization. Mol Cell (2017) 65:361-70. doi:10.1016/j.molcel.2016.12.005

118. Cheng LC, Tan VM, Ganesan S, Drake JM. Integrating phosphoproteomics into the clinical management of prostate cancer. Clin Transl Med (2017) 6:9. doi:10.1186/s40169-017-0138-5

119. Byrne JC, Downes MR, O’Donoghue N, Fitzpatrick JM, Dunn MJ, Watson RW. Fasting status as a consideration for human serum collection and preparation prior to depletion and analysis. Electrophoresis (2008) 29:3055-9. doi:10.1002/elps.200700933

120. M'Koma AE, Blum DL, Norris JL, Koyama T, Billheimer D, Motley S, et al. Detection of pre-neoplastic and neoplastic prostate disease by MALDI profiling of urine. Biochem Biophys Res Commun (2007) 353:829-34. doi:10.1016/j. bbrc.2006.12.111

121. Sardana G, Jung K, Stephan C, Diamandis EP. Proteomic analysis of conditioned media from the PC3, LNCaP, and 22Rv1 prostate cancer cell lines: discovery and validation of candidate prostate cancer biomarkers. J Proteome Res (2008) 7:3329-38. doi:10.1021/pr8003216

122. Sharma VK, Vouros P, Glick J. Mass spectrometric based analysis, characterization and applications of circulating cell free DNA isolated from human body fluids. Int J Mass Spectrom (2011) 304:172-83. doi:10.1016/j.ijms.2010. 10.003

123. Elshimali YI, Khaddour H, Sarkissyan M, Wu Y, Vadgama JV. The clinical utilization of circulating cell free DNA (CCFDNA) in blood of cancer patients. Int J Mol Sci (2013) 14:18925-58. doi:10.3390/ijms140918925

124. Siravegna G, Marsoni S, Siena S, Bardelli A. Integrating liquid biopsies into the management of cancer. Nat Rev Clin Oncol (2017) 14:531-48. doi:10.1038/ nrclinonc.2017.14

125. Scher HI, Graf RP, Schreiber NA, McLaughlin B, Lu D, Louw J, et al. Nuclearspecific AR-V7 protein localization is necessary to guide treatment selection in metastatic castration-resistant prostate cancer. Eur Urol (2017) 71:874-82. doi:10.1016/j.eururo.2016.11.024

126. Danila DC, Heller G, Gignac GA, Gonzalez-Espinoza R, Anand A, Tanaka E, et al. Circulating tumor cell number and prognosis in progressive castration-resistant prostate cancer. Clin Cancer Res (2007) 13:7053-8. doi:10.1158/ 1078-0432.CCR-07-1506

127. Tang MK, Wong AS. Exosomes: emerging biomarkers and targets for ovarian cancer. Cancer Lett (2015) 367:26-33. doi:10.1016/j.canlet.2015. 07.014

128. Soung YH, Ford S, Zhang V, Chung J. Exosomes in cancer diagnostics. Cancers (Basel) (2017) 9. doi:10.3390/cancers9010008

129. Duijvesz D, Burnum-Johnson KE, Gritsenko MA, Hoogland AM, Vredenbregt-van den Berg MS, Willemsen R, et al. Proteomic profiling of 
exosomes leads to the identification of novel biomarkers for prostate cancer. PLoS One (2013) 8:e82589. doi:10.1371/journal.pone.0082589

130. Øverbye A, Skotland T, Koehler CJ, Thiede B, Seierstad T, Berge V, et al. Identification of prostate cancer biomarkers in urinary exosomes. Oncotarget (2015) 6:30357-76. doi:10.18632/oncotarget.4851

131. Worst TS, von Hardenberg J, Gross JC, Erben P, Schnölzer M, Hausser I, et al. Database-augmented mass spectrometry analysis of exosomes identifies claudin 3 as a putative prostate cancer biomarker. Mol Cell Proteomics (2017) 16:998-1008. doi:10.1074/mcp.M117.068577

132. Kitano H. Computational systems biology. Nature (2002) 420:206-10. doi:10.1038/nature01254
Conflict of Interest Statement: The authors declare that the research was conducted in the absence of any commercial or financial relationships that could be construed as a potential conflict of interest.

Copyright (c) 2018 Ramroop, Stein and Drake. This is an open-access article distributed under the terms of the Creative Commons Attribution License (CC BY). The use, distribution or reproduction in other forums is permitted, provided the original author(s) and the copyright owner are credited and that the original publication in this journal is cited, in accordance with accepted academic practice. No use, distribution or reproduction is permitted which does not comply with these terms. 